\title{
Microglia and Microglia-Like Cells: Similar but Different
}

\author{
Miguel A. Cuadros*, M. Rosario Sepulveda, David Martin-Oliva, José L. Marín-Teva and \\ Veronika E. Neubrand
}

Department of Cell Biology, Faculty of Science, University of Granada, Granada, Spain

Microglia are the tissue-resident macrophages of the central nervous parenchyma. In mammals, microglia are thought to originate from yolk sac precursors and posteriorly maintained through the entire life of the organism. However, the contribution of microglial cells from other sources should also be considered. In addition to "true" or "bonafide" microglia, which are of embryonic origin, the so-called "microglia-like cells" are hematopoietic cells of bone marrow origin that can engraft the mature brain mainly under pathological conditions. These cells implement great parts of the microglial immune phenotype, but they do not completely adopt the "true microglia" features. Because of their pronounced similarity, true microglia and microglia-like cells are usually considered together as one population. In this review, we discuss the origin and development of these two distinct cell types and their differences. We will also review the factors determining the appearance and presence of microglia-like cells, which can vary among species. This knowledge might contribute to the development of therapeutic strategies aiming at microglial cells for the treatment of diseases in which they are involved, for example neurodegenerative disorders like Alzheimer's and Parkinson's diseases.

Urte Neniskyte,

Vilnius University, Lithuania

Daniel Erny,

University of Freiburg Medical Center,

Germany

Keywords: microglia, microglia-like cells, yolk sac, bone marrow, hematopoietic stem cells

${ }^{*}$ Correspondence:

Miguel A. Cuadros

macuadro@ugr.es

Specialty section:

This article was submitted to

Non-Neuronal Cells,

a section of the journal

Frontiers in Cellular Neuroscience

Received: 16 November 2021

Accepted: 17 January 2022

Published: 07 February 2022

Citation:

Cuadros MA, Sepulveda MR, Martin-Oliva D, Marin-Teva JL and Neubrand VE (2022) Microglia and

Microglia-Like Cells: Similar But

Different.

Front. Cell. Neurosci. 16:816439. doi: 10.3389/fncel.2022.816439

\section{INTRODUCTION}

Macrophages constitute a heterogeneous population of immune cells of the myeloid lineage, involved in phagocytic and other functions, like cell signaling and release of biologically active molecules. Specific tissue-resident macrophages are located in certain tissues/organs and represent particular macrophage subtypes.

At least four types of macrophages have been identified in the mature and developing central nervous system (CNS; Figure 1): meningeal macrophages, perivascular macrophages, choroid plexus macrophages, and microglia (Goldmann et al., 2016; Herz et al., 2017; Lopez-Atalaya et al., 2018). Because the first three types are located

\footnotetext{
Abbreviations: 4'OHT, hydroxytamoxifen; AGM, aorta-gonad-mesonephros; BAM, border-associated macrophages; BBB, blood-brain barrier; BM, bone marrow; BMDM, bone marrow-derived macrophages; CNS, central nervous system; CSF-1, colony stimulating factor-1; DTR, diphtheria toxin receptor; EAE, experimental autoimmune encephalitis; EM, embryonic macrophages; EMP, erythromyeloid progenitor; FIRE, fms-intronic regulatory element; GFP, green fluorescent protein; HSC, hematopoietic stem cells; HVTK, herpesvirus thymidine kinase; IL-34, interleukin-34; LPS, lipopolysaccharide; MLC, microglia-like cells; PBI, posterior blood islands; PLM, posterior lateral mesoderm; RBI, rostral blood islands; TGF- $\beta$, transforming growth factor- $\beta$; VDA, ventral wall of dorsal aorta; YS, yolk sac.
} 
at the borders of the nervous parenchyma, they are known as border-associated macrophages (BAM) or CNS-associated macrophages (CAM). In contrast, microglia are situated within the nervous parenchyma. Although BAM and microglia share some features, like the expression of the fractalkine receptor CX3CR1, both of them exhibit their own characteristics. For instance, microglia express the specific marker Tmem119, which is not expressed in BAMs ( $\mathrm{Li}$ and Barres, 2018). A recent study reveals that both BAM and microglial cells derive from the yolk sac (YS) and acquire their phenotype depending on their genotype and location cues (Utz et al., 2020).

Hence, microglia are the resident macrophages of the nervous parenchyma. They can be distinguished from other tissueresident and peripheral macrophages because of their embryonic origin from the YS, maintenance, and immunophenotype, as will be discussed in the next sections. They participate in the surveillance, development, homeostasis, protection and functional integrity of the CNS (Hanisch, 2013; Casano and Peri, 2015) being involved in many CNS disorders (Amici et al., 2017).

Microglial cells show a variety of morphological and immunological phenotypes in the developing CNS and mature healthy brain, with additional phenotypes in the pathological/aging brain (Deczkowska et al., 2018; Savage et al., 2019; Stratoulias et al., 2019). During development predominate microglial cells with a round morphology and short and broad processes ("amoeboid microglia"), while microglia in the adult brain frequently show thin processes with more or less profuse ramifications ("ramified microglia"; Cuadros and Navascues, 1998; Smolders et al., 2019). Cell marking experiments (e.g., Leong and Ling, 1992) have established that amoeboid microglia can transform into ramified microglia.

Techniques such as microarrays, bulk RNA-seq or single-cell RNA-seq, have revealed the presence of different subsets of microglia at the molecular level (Hammond et al., 2019; Gerrits et al., 2020; Masuda et al., 2020). They go through a stepwise developmental program during their maturation in which each phase is characterized by a different set of gene expressions (Matcovitch-Natan et al., 2016). The stages of microglial development in the mouse brain are: early microglia (approximately from E10.5 to E14), pre-microglia (approximately from E14 to the 1st postnatal week), and adult microglia (four or more postnatal weeks; Matcovitch-Natan et al., 2016; Thion et al., 2018b; Smolders et al., 2019). Apparently, miRNAs are involved in regulating the gene expression in microglia (Varol et al., 2017; Guo et al., 2019).

In addition to microglia of embryonic origin, the adult CNS also contains hematopoietic cells that can permanently engraft in the nervous parenchyma under certain conditions and acquire features similar to embryonic microglia (Varvel et al., 2012; Sevenich, 2018), as will be discussed in detail later in this review. The reported heterogeneity shown by microglial cells (Zia et al., 2020) may "hide" the presence of such cells that presumably were frequently included within the general term of "microglia". Although microglial cells of embryonic origin share many markers, like CD11b, F4/80, CX3CR1, and Iba-1, with other macrophages and with the hematopoietic cells engrafting the nervous parenchyma in adulthood, the engrafting cells express high levels of CD45, whereas embryonic microglia express lower levels (Amici et al., 2017).

Gene expression analysis (reviewed in Gerrits et al., 2020) has revealed that the engrafted cells present molecular and functional differences compared with adult microglia of embryonic origin, despite the fact that they adopt a similar morphology (Bruttger et al., 2015; Bennett et al., 2018; Cronk et al., 2018; Shemer et al., 2018; Tables 1 and 2). The term "microglia" (or "true microglia" or "bona fide microglia") is reserved for myeloid cells from the YS that colonize the nervous tissue during embryonic stages and self-renew by proliferation, without the participation of new myeloid cells under physiological conditions. In contrast, myeloid cells derived from bone marrow (BM) that colonize the nervous parenchyma in response to pathological situations and establish a permanent population within the brain parenchyma (Cronk et al., 2018; Lund et al., 2018) are called bone marrowderived microglia or microglia-like cells (MLC). In this article, we will use the term MLC, as in our opinion this reflects not only their different origin but also their slightly different characteristics.

In this review, we discuss the origin, differences, and similarities of microglia and MLC. Although we mainly center on the microglia of mice, we also refer to other species, including humans.

\section{MICROGLIA ARE CELLS OF HEMATOPOIETIC LINEAGE}

The first extensive description of microglial cells (del RioHortega, 1919, translated and annotated in Sierra et al., 2016; del Rio-Hortega, 1932) already proposed that microglial cells likely originated outside the nervous parenchyma. More recent evidence has strengthened this idea. Although different sources for the origin of microglial cells have been proposed (see Kaur et al., 2017), currently it is firmly established that microglial cells are related to the hematopoietic lineage.

Microglial cells are labeled with many reagents, which also mark hematopoietic cells (Table 3). The existence of reagents recognizing mature microglia but not embryonic microglia, e.g., anti-P2ry12 and anti-Tmem119 (Bennett et al., 2016), indicate that the transcriptome of mature microglia is different from the one of developing microglia and other tissue macrophages (Varol et al., 2017; Li et al., 2019).

Additional proofs were obtained from PU.1-mutant mice. PU.1 is a transcription factor product of the Sfpil gene, which is expressed in cells of hematopoietic lineage. Lack of PU.1 results in mice devoid of macrophages, eosinophils, B cells, and the impairment of the development of neutrophils and T lymphocytes. Interestingly, PU.1 $1^{-1-}$ mice do not possess microglia, confirming their hematopoietic origin (McKercher et al., 1996; Kierdorf et al., 2013a).

Mutations affecting the expression of hematopoietic factors also disturb microglial cells. Accordingly, macrophage maturation is impaired and microglia numbers are reduced in the osteopetrotic (op/op) mice, bearing a spontaneous null mutation 


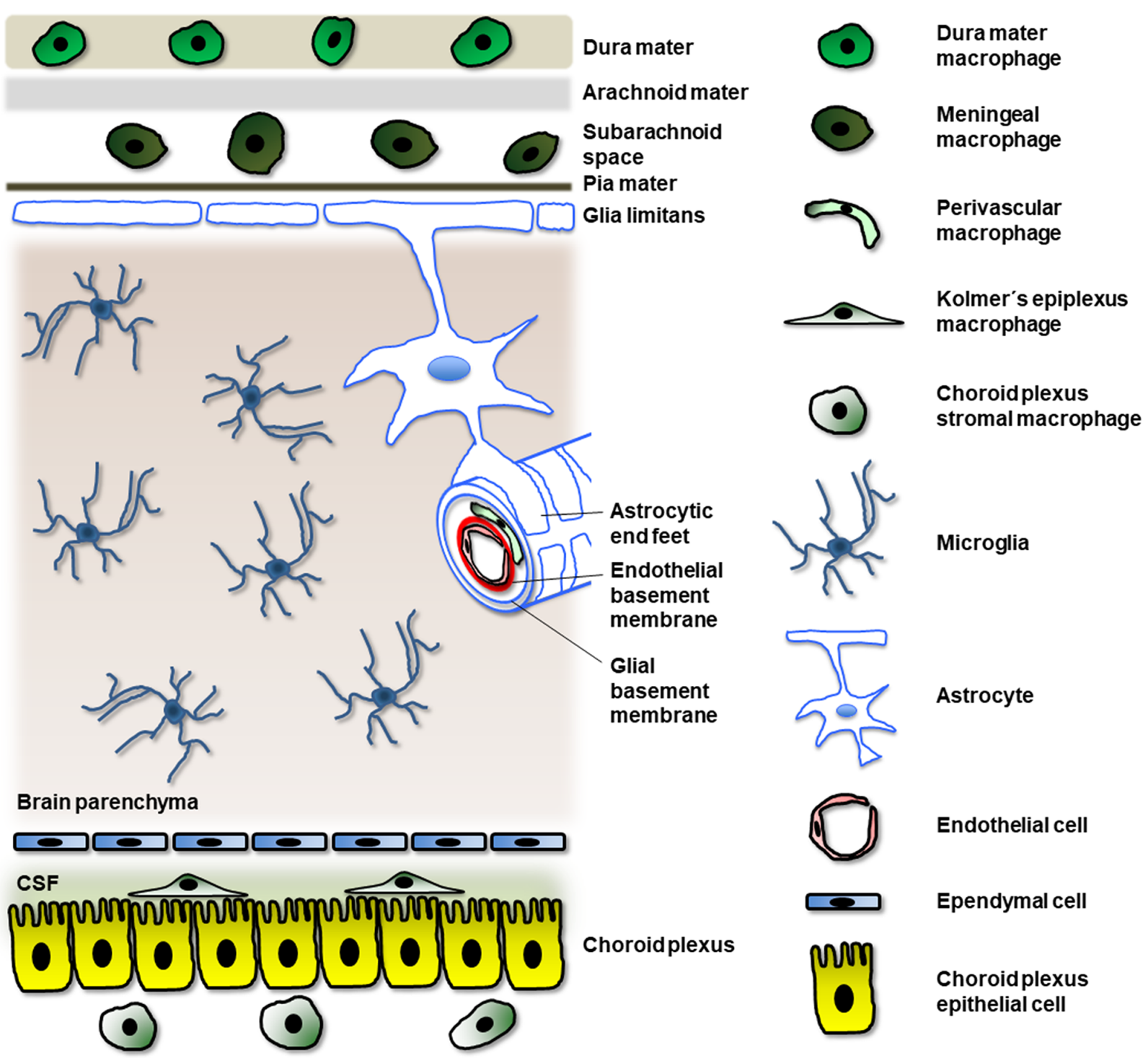

FIGURE 1 | Localization of different myeloid cells related to macrophages in the CNS. Meningeal macrophages locate in the subarachnoidal space while other macrophages appear in other regions of the meninges (for example, dura mater macrophages). Perivascular macrophages localize between the endothelial and glial basement membranes (note that pericytes in the perivascular space of the blood vessel have not been represented for clarity). Kolmer's epiplexus macrophages are found above the choroid plexus epithelial cells and in contact with the cerebrospinal fluid (CSF); they apparently derive from choroid plexus stromal macrophages located underneath the choroid plexus epithelial cells. Finally, the sole myeloid cells in the nervous parenchyma are microglial cells.

TABLE 1 | Representative genes with higher expression levels in YS-derived microglia (healthy adult) than in engrafted brain macrophages/microglia-like cells.

\begin{tabular}{|c|c|c|c|}
\hline Gene & Protein class & Biological function & Function in microglia \\
\hline P2ry12 & Purinergic receptor & Cell migration Response to ADP/ATP & Regulation of microglial migration \\
\hline Sall1 & Transcriptional regulator & Developmental processes & Regulation of microglial identity and state \\
\hline Siglec-H & Sialic acid receptor & $\begin{array}{l}\text { Cargo receptor } \\
\text { Cell adhesion } \\
\text { Endocytosis }\end{array}$ & Recognition of phagocytic targets \\
\hline Tmem119 & $\begin{array}{l}\text { Transmembrane } \\
\text { protein }\end{array}$ & $\begin{array}{l}\text { Biomineralization } \\
\text { Differentiation }\end{array}$ & Unknown \\
\hline
\end{tabular}

in the gene that codifies the colony-stimulating factor-1 (CSF-1; Kondo et al., 2007). In contrast, Csflr ${ }^{-1-}$ mice, that lack the CSF-1 receptor, show a nearly total depletion of microglia. This indicates that CSFR1 can also bind to another ligand important for microglia development, identified as interleukin-34 (IL-34; Greter et al., 2012; Wang et al., 2012). In fact, deletion of IL-34 
TABLE 2 | Representative genes showing higher expression levels in engrafted brain macrophages/microglia-like cells than in YS-derived microglia (healthy adult).

\begin{tabular}{|c|c|c|c|}
\hline Gene & Protein class & Biological function & Function in microglia \\
\hline$A \times l$ & $\begin{array}{l}\text { Tyrosine kinase } \\
\text { receptor }\end{array}$ & $\begin{array}{l}\text { Regulation of phagocytosis and macrophage polarization } \\
\text { Apoptotic cell clearance }\end{array}$ & $\begin{array}{l}\text { Regulation of } \\
\text { phagocytosis }\end{array}$ \\
\hline Ccr2 & Chemokine receptor & Chemotaxis & $\begin{array}{l}\text { Chemotaxis of myeloid } \\
\text { cells }\end{array}$ \\
\hline Cxcr4 & $\begin{array}{l}\text { Chemokine (vgr. SDF-1) } \\
\text { receptor }\end{array}$ & Chemotaxis & Nearly absent \\
\hline Cybb & Cytochrome & Regulation of ROS generation & ROS generation \\
\hline
\end{tabular}

Data in Table 1 and 2 from Shemer et al. (2018), Buttgereit et al. (2016), and UniProt database (https://www.uniprot.org/uniprot/, accessed 09 October 2021).

TABLE 3 | Common microglial markers.

\begin{tabular}{|c|c|c|c|}
\hline Marker & Labeling on microglia & Labeling of non-microglial cells & Reference \\
\hline CD68 immunohistochemistry & $\begin{array}{l}\text { Endosomes and lysosomes of } \\
\text { activated microglia. }\end{array}$ & $\begin{array}{l}\text { Blood monocytes and peripheral } \\
\text { macrophages. }\end{array}$ & Santos et al. (2010) \\
\hline F4/80 immunohistochemistry & $\begin{array}{l}\text { Amoeboid and ramified microglia } \\
\text { (original batch). } \\
\text { Amoeboid microglia (most current } \\
\text { batches). }\end{array}$ & Peripheral macrophages. & $\begin{array}{l}\text { Perry et al. (1985), } \\
\text { Santos et al. (2008) }\end{array}$ \\
\hline Iba-1 immunohistochemistry & $\begin{array}{l}\mathrm{Ca}^{2+} \text {-binding protein in microglia } \\
\text { (cytoplasm and membrane). } \\
\text { Staining of amoeboid and ramified } \\
\text { microglia. }\end{array}$ & Peripheral macrophages. & Ito et al. (1998) \\
\hline $\begin{array}{l}\text { Lectin ISB4 from Griffonia } \\
\text { simplicifolia }\end{array}$ & $\begin{array}{l}\text { Plasma and Golgi membranes. } \\
\text { Strong labeling of amoeboid and } \\
\text { poorly ramified microglia. } \\
\text { Weak staining of fully ramified } \\
\text { microglia. }\end{array}$ & $\begin{array}{l}\text { Endothelial and blood cells. } \\
\text { Peripheral macrophages. }\end{array}$ & Kaur et al. (2001) \\
\hline $\begin{array}{l}\text { Nucleoside diphosphatase (NDP) } \\
\text { histochemistry }\end{array}$ & $\begin{array}{l}\text { Plasma membrane of amoeboid } \\
\text { and ramified microglia. }\end{array}$ & $\begin{array}{l}\text { Endothelial and blood cells. } \\
\text { Intracellular staining of neurons. }\end{array}$ & Murabe and Sano (1982) \\
\hline P2ry12 immunohistochemistry & $\begin{array}{l}\text { Purinergic receptor in ramified } \\
\text { microglia. }\end{array}$ & $\begin{array}{l}\text { No labeling in peripheral } \\
\text { macrophages. }\end{array}$ & Butovsky et al. (2014) \\
\hline $\begin{array}{l}\text { Thiamine pyrophosphatase (TPP) } \\
\text { histochemistry }\end{array}$ & $\begin{array}{l}\text { Plasma membrane of ramified } \\
\text { microglia. }\end{array}$ & $\begin{array}{l}\text { Endothelial and blood cells. } \\
\text { Intracellular staining of neurons. }\end{array}$ & Murabe and Sano (1981) \\
\hline Tmem119 immunocytochemistry & $\begin{array}{l}\text { Transmembrane protein in ramified } \\
\text { microglia. }\end{array}$ & $\begin{array}{l}\text { No labeling in peripheral } \\
\text { macrophages. }\end{array}$ & Bennett et al. (2016) \\
\hline
\end{tabular}

resulted in the absence of microglia in a great part of the brain (Wang et al., 2012). Interestingly, not all microglial cells have the same requirements for CSF-1 and IL-34, as these two ligands affect differently microglia in the white and gray matter of the brain (Easley-Neal et al., 2019) and the development of mouse cerebellar microglia is not affected by IL-34 deficiency (Kana et al., 2019).

Therefore, multiple evidences support that microglia have a hematopoietic origin. In agreement with the conceptual framework of the mononuclear phagocyte system (van Furth et al., 1972), microglia are likely to derive from circulating monocytes (see Ginhoux and Jung, 2014). In fact, carbon labeling of blood monocytes results in the finding of some labeled amoeboid and ramified microglial cells in the corpus callosum of postnatal rats (Ling, 1979; Ling et al., 1980). Therefore, it was postulated that microglial cells, like other tissue-resident macrophages, were of monocytic origin (reviewed in Ginhoux et al., 2013).

However, this view has been challenged by reports using lineage-tracing techniques revealing that microglia, although of hematopoietic origin, originate independently of monocytes (reviewed, among many others, by Prinz et al., 2017 and Thion et al., 2018a), and that they are not replaced by BM-derived monocytes under physiological conditions, unlike other tissue-resident macrophages (Marquez-Ropero et al., 2020).

\section{Brief Description of Hematopoiesis in Mice}

Because of the relation of microglial cells with hematopoiesis, we will shortly describe the development of hematopoiesis in the mouse, mainly focusing on macrophages.

Three different waves (or phases) of hematopoiesis have been described during mouse development. The first one, called the primitive hematopoietic program by Hoeffel and Ginhoux (2018), occurs in the YS and starts at E7-7.5. This phase is produced by hematopoietic precursors in the YS (denominated primitive myeloid precursors by McGrath et al., 2015) that differentiate as primitive erythrocytes, megakaryocytes, and macrophages.

The second wave begins around E8 and is produced by erythromyeloid progenitors (EMP, McGrath et al., 2015) located in the YS, giving rise to all types of hematopoietic cells (definitive erythrocytes and leukocytes), including fetal monocytes. Some EMP invade the liver rudiment and 
other hematopoietic organs, such as the spleen and thymus, during the development of the embryo and become the founder cells of the "transient definitive hematopoiesis" (Hoeffel and Ginhoux, 2018).

Finally, hematopoietic stem cells (HSC) produced in the aorta-gonad-mesonephros region (AGM) of the embryo start the third wave, or "definitive hematopoiesis", at E10.5 (Hoeffel and Ginhoux, 2018). HSC will settle in the fetal liver (the main hematopoietic organ during most of the gestation period) and other hematopoietic organs of the embryo where they mature and differentiate to give rise to definitive erythrocytes and all myeloid cells, including monocytes. HSC from the fetal liver will finally colonize the $\mathrm{BM}$, the only hematopoietic organ of the adult, where hematopoiesis starts at around the second postnatal week.

Therefore, macrophages are produced directly from their progenitors during the first hematopoietic and perhaps during the second wave, without passing through a monocyte stage, while they originate from monocytes during the second and third waves. Consequently, there are two different ways of macrophage production, in agreement with studies by Takahashi et al. (1989, 1996), which reveal the presence of macrophages in rodent embryos before the appearance of monocytes.

\section{Brief Description of Hematopoiesis in Non-mammalian Vertebrates}

Although this scheme of hematopoiesis seems to be valid for other mammals, including humans (Tavian et al., 2010; Bian et al., 2020), differences affecting the development of macrophages and microglial cells have been reported in non-mammalian vertebrates. For example, the primitive hematopoiesis of the zebrafish originates in two different regions of the lateral plate mesoderm, anterior (rostral blood islands, RBIs) and posterior (posterior lateral mesoderm, PLM) to the yolk ball (equivalent to the YS of amniotes, as in anamniote vertebrates there is no YS of extra-embryonic tissues). The RBIs give rise essentially to macrophages, while the PLM originates fundamentally primitive erythrocytes. Pre-macrophages from the RBIs enter the yolk ball, where they differentiate, and later colonize the cephalic tissues, including the brain and retina (Herbomel et al., 1999; Bertrand et al., 2007; Bertrand and Traver, 2009; Gore et al., 2018). Therefore, the RBIs would be the site of origin of primitive macrophages and embryonic microglia (Herbomel et al., 2001; Gore et al., 2018). The second wave of hematopoiesis, apparently equivalent to the transient hematopoiesis described in the mouse, is produced by EMP arising in the posterior blood island (PBI). Finally, the definitive wave of hematopoiesis originates from the ventral wall of the dorsal aorta (VDA), producing HSCs capable of giving rise to all mature blood cells and microglial cells (Xu et al., 2015).

Birds are amniote vertebrates with development of hematopoiesis comparable to the one described in mice. In birds, YS macrophages and microglial cells are replaced during development by cells derived from intraembryonic precursors (Garceau et al., 2015).

\section{ORIGIN, DEVELOPMENT, AND MAINTENANCE OF MICROGLIA}

The presence of brain macrophages and/or early microglia in the developing brain has been described in all vertebrates: zebrafish (Herbomel et al., 2001), amphibians (Goodbrand and Gaze, 1991), birds (Cuadros et al., 1993), rats (Sorokin et al., 1992), mice (Ginhoux et al., 2010; Ginhoux and Prinz, 2015) and humans (Andjelkovic et al., 1998; Verney et al., 2010). This widespread presence suggests that they are important for the development of the normal organization of the nervous system, sculpting the early stages of the nervous system (Ginhoux and Prinz, 2015). For example, the ablation of brain macrophage/microglia modifies the populations of sensory neurons (Angelim et al., 2018).

However, it has been reported that the lack of early brain macrophages and embryonic microglia does not produce gross abnormalities in the brain during embryonic stages (Patkar et al., 2021). Thus, embryos pharmacologically depleted of microglia survive until postnatal age without apparent morphological changes in the adult brain (Rosin et al., 2018). The authors detected an increase in neural cell death and cell debris in the developing brain of microglia-depleted embryos. However, this increase is no longer apparent in the adult brain, indicating that dead cells and cell debris are finally removed, suggesting that other cells replace the clearing role of microglia (Kierdorf and Prinz, 2017). In fact, despite the nearly complete depletion of microglia in $C s f r-1^{-1-}$ mice, the brain shows a normal organization during the prenatal period, although its cytoarchitecture is severely perturbed in the 3rd postnatal week (Erblich et al., 2011). Similarly, neurogenesis and overall patterning of the brain are not disturbed in embryos depleted of microglia during most parts of embryonic development (Squarzoni et al., 2014). The authors indicate, however, that some cortex interneurons and wiring processes, such as the dopaminergic projection invading the striatum, are affected by the absence of microglia. Other authors show that the absence of microglia also disturbs the fasciculation of callosal axons (PontLezica et al., 2014).

Thus, the presence of brain macrophages and/or microglial cells seems to be dispensable for the gross development of the brain and the lack of microglia does not produce evident abnormalities in the brain architecture during the embryonic period.

\section{Microglial Origin From the Yolk Sac}

Although previous studies have already proposed that microglial cells might be of YS origin (Cuadros et al., 1993; Alliot et al., 1999), direct evidence of this origin was reported in 2010 using genetic labeling of microglial precursors (Ginhoux

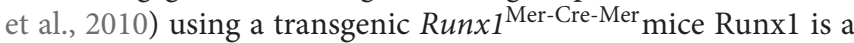
transcription factor needed for hematopoiesis (Yzaguirre et al., 2017; Menegatti et al., 2019) whose expression at E7.5 is restricted to the YS; one day later, Runx1 expression is observed in the AGM region (Samokhvalov et al., 2007). Administration of 4-hydroxytamoxifen (4'OHT) to induce recombination between E7.0 and E7.5 produces permanent labeling of more than $30 \%$ 
of the microglial cells in the adult brain; in contrast, circulating leukocytes and monocytes are not labeled. The injection of 4'OHT after E7.5 results in a progressive reduction in the number of labeled microglial cells in the adult and the labeling of HSC-derived cells (Ginhoux et al., 2010). Thus, the authors conclude that microglial cells originate from cells produced around E7.5 in the YS and not from blood monocytes, i.e., that microglial cells derive from primitive myeloid precursors, corresponding to the first wave of hematopoiesis.

Other lineage tracing studies using similar approaches obtain slightly different results, as the mapping is related to the particular expression pattern of each gene: Runx1 expression is limited to precursors budding from the hemogenic endothelium, while $c$-Kit, another gene used in the mapping studies (see below), is expressed by all hematopoietic progenitors (Hoeffel and Ginhoux, 2015). The analysis of Kit ${ }^{\text {Mer-Cre-Mer }}$ mice shows that similar numbers $(\approx 50 \%)$ of microglial cells are labeled after injection at E7.5 or E8.5 (Sheng et al., 2015), indicating that microglia could derive from primitive myeloid precursors and EMP. Gomez Perdiguero et al. (2015) discriminate between cells originated from YS-derived cells and HSC progenitors using Csfr $1^{\text {Mer-Cre-Mer }}$ and Flt $3^{\text {Cre }}$ mice (Flt3 is mainly expressed in cells derived from HSC progenitors). Confirming former studies (Schulz et al., 2012), this report reveals that intraembryonic HSC account only for a minor fraction of microglia. Similarly, another study concludes that most macrophages, except microglia, initially derive from embryonic precursors that are later replaced by BM-derived macrophages (Sheng et al., 2015).

The above reports used genetic lineage tracing studies, a very powerful tool to investigate the fate of progenitors in vivo, but with certain limitations (McGrath et al., 2015). For instance, the efficiency of recombination of developing cells will produce distortions on the contribution of progenitors to the final population (Samokhvalov et al., 2007; Gomez Perdiguero et al., 2015), explaining why a fraction of macrophages remain unlabeled. In this sense, it is worthy to note that the authors of the first report (Ginhoux et al., 2010) affirm that their model probably underestimates the contribution of Runx1+ cells to adult microglia and that they cannot exclude the contribution of non-labeled precursors to the ontogeny of microglia. Moreover, a significant proportion (7-10\%) of adult HSC were of extraembryonic origin, raising the question that part of the Runx1+ labeled microglia in the adult are likely to originate from YS precursors that participate in the definitive hematopoiesis (Samokhvalov et al., 2007). In this sense, a review about the ontogeny of resident macrophages (Ginhoux and Guilliams, 2016) states that, "it remains possible that a minor population of adult microglia, [...] might derive from non-YS progenitors recruited later during development". Additional caveats about the results obtained from lineage studies have been expressed (Epelman et al., 2014; McKinsey et al., 2020).

Other experiments establish that the first macrophage population appearing during development are of YS origin and evolve independently of the transcription factor Myb, a critical regulator of hematopoiesis; the second population is constituted by macrophages derived from HSCs and require Myb. Microglial cells originate from the first population and are not replaced by Myb-dependent hematopoietic cells, as normal numbers of microglial cells are detected in $c-M y b^{-1-}$ mice (Schulz et al., 2012).

The first microglia precursors are EMP detected in the YS at E8 $\left(\mathrm{CD}_{4} 5^{-}, \mathrm{c}-\mathrm{kit}^{+}\right)$. Later on, A1 cells $\left(\mathrm{CD} 45^{+}, \mathrm{c}-\mathrm{kit}^{-}\right.$, $\mathrm{CX} 3 \mathrm{CR} 1^{-}$) emerge, which give rise to microglia precursor A2 cells $\left(\mathrm{CD} 45^{+}, \mathrm{c}^{-\mathrm{kit}^{-}}, \mathrm{CX} 3 \mathrm{CR} 1^{+}\right)$. Both A1 and A2 cells appear in the YS and are able to differentiate into microglial cells in organotypic hippocampal slice cultures. A2 cells enter the cephalic mesenchyme and produce microglial cells in the developing brain from E9.5 and onwards. The absence of PU.1 affects both A1 and A2 cells, resulting in the complete lack of microglial cells. In contrast, the lack of Irf8 gene, encoding another transcription factor of myeloid cells, only reduces the number of microglia. Careful analysis shows that A1 cells are unaffected by the lack of Irf8, but that A2 cells are severely depleted under the same conditions, suggesting a role of Irf8 in microglial maturation (Kierdorf et al., 2013a). The remaining A2 cells can proliferate and produce microglial cells, however with phenotypical and morphological alterations (Minten et al., 2012).

Other studies reinforce the idea that microglial cells and embryonic macrophages are related. For example, E10.5 Runx1 $1^{-/}$embryos, which do not contain embryonic macrophages, also lack microglia precursors (Ferrero et al., 2018) and the lack of embryonic macrophages accompany the depletion of microglial cells in the developing brain (Angelim et al., 2018; Rojo et al., 2019).

\section{Entry and Colonization of the Developing Brain}

Microglia progenitors from YS invade the developing CNS to become microglial cells at E9.5 (Ginhoux et al., 2010; Kierdorf et al., 2013a; Figure 2), before the establishment of the bloodbrain barrier (BBB), which begins around E15 in mice (Daneman et al., 2010). As the developing brain is colonized by YS macrophages before any other structures of the embryo (Sorokin et al., 1992), it is reasonable to assume that these cells are attracted to the developing brain before they are attracted to any other tissue. The invasion of the developing brain raises questions about whether there is a specific subpopulation of embryonic macrophages for invading the neuroepithelium and about the identity of factors eliciting the entry within the developing CNS.

Regarding the first question, a subtype of embryonic macrophages, specific for entering the brain and giving rise to microglia, is described in the zebrafish (Rossi et al., 2015). However, the existence in mammals of a subpopulation of macrophages in the embryo devoted to colonizing the brain remains to be demonstrated.

Blood circulation can also affect macrophage colonization, as shown by the fact that $N c x-1^{-/-}$mice, characterized by loss of heart beating and impaired development of the circulatory system, have no detectable brain macrophages/microglia at E9.5-10.5 (Ginhoux et al., 2010). In contrast, early colonization of zebrafish midbrain by microglia precursors is described as circulation-independent (Xu et al., 2016). In addition, entry into the avian CNS seems to be independent of the establishment 


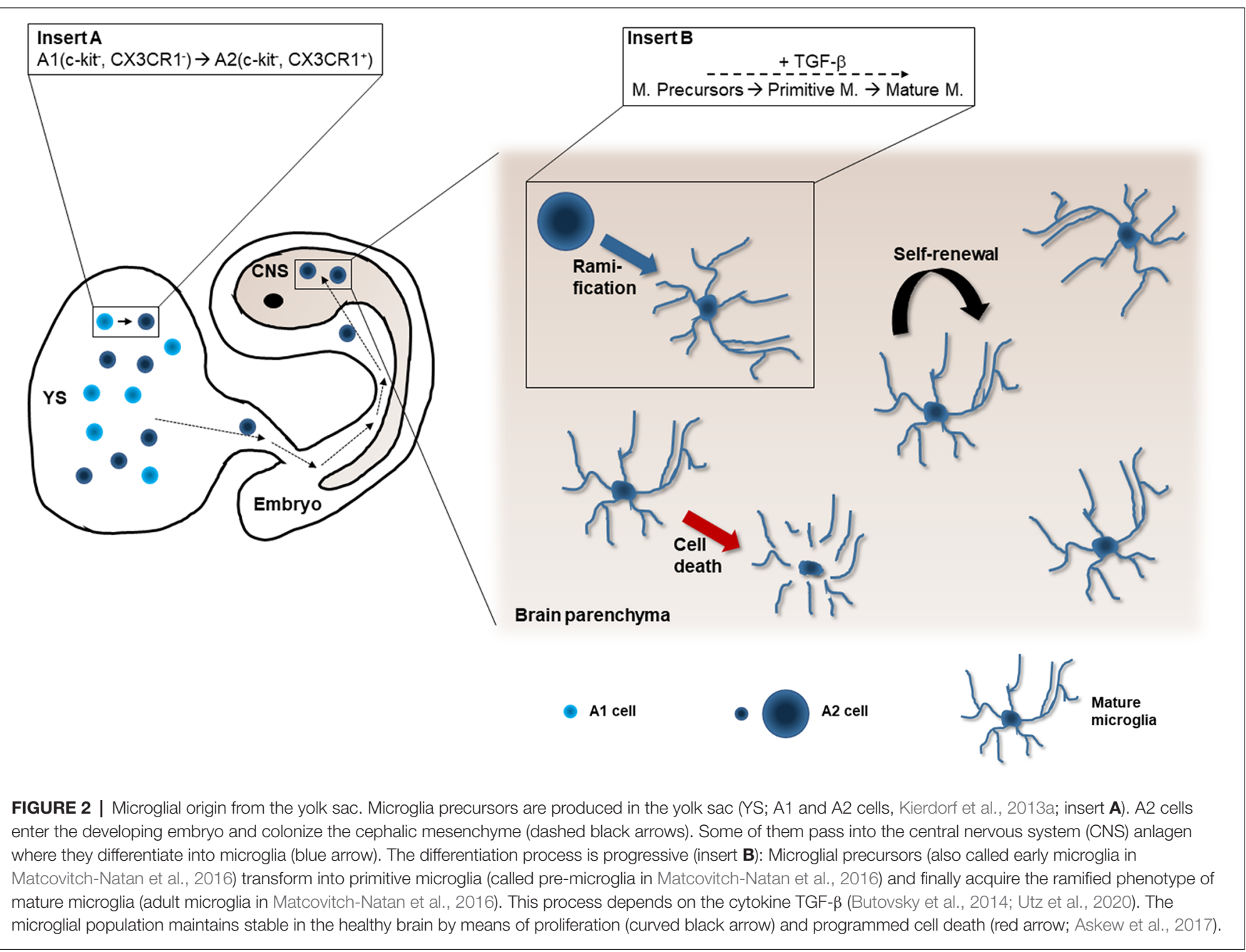

of circulation, as macrophage invasion precedes the presence of vascular buds into the neuroepithelium (Cuadros et al., 1993) and cells of YS origin colonize the avian avascular retina (Cuadros et al., 1991). Studies on the early appearance of brain macrophages in rodents and humans (e.g., Sorokin et al., 1992; Andjelkovic et al., 1998; Kierdorf et al., 2013a; Menassa and Gomez-Nicola, 2018) do not show a clear correlation between the appearance of these cells within the neuroepithelium and blood vessel development. It is possible that the emigration of early macrophages from the YS into the embryo would require functional circulation (Stremmel et al., 2018). However, these cells might leave the blood vessels after reaching the embryo mesenchyme and migrate to the neuroepithelium independently of the vasculature.

Cell death has frequently been associated with the presence of macrophages. Lysophosphatidylcholine, a lipid product released by apoptotic cells that attracts monocytic cells (Lauber et al., 2003), promotes the migration of macrophages into the zebrafish midbrain (Xu et al., 2016). Other authors have also reported that altering the rate of cell death also changes the number of macrophage/microglial cells in the zebrafish brain (Casano et al., 2016; Wu et al., 2018). It has been proposed that microglia precursors colonize the zebrafish brain by two types of mechanisms: one apoptosis-dependent and another one apoptosis-independent. The first one would happen early in development and might be driven by chemoattractants released by dying cells produced during early neurogenesis. The apoptosis-independent migration might occur later during development and depend on other factors, such as IL-34 (Xu et al., 2016; Wu et al., 2018). In higher vertebrates (including rodents and mammals), brain macrophages appear independently of the abundance of previous cell death (Cuadros et al., 1993; Santos et al., 2008; Toyoshima et al., 2012), although some reports affirm that microglial cells appear coincidentally with cell death in the rat (Ashwell, 1991) and human (Rakic and Zecevic, 2000) telencephalon.

The spreading of microglial cells through the nervous parenchyma may be influenced by the distribution of migratory substrates, such as nerve fibers, blood vessels, or neuroglia cells (Navascues et al., 1995; Marin-Teva et al., 1999; SanchezLopez et al., 2004; Mondo et al., 2020), and by chemoattractive and chemorepellent molecules (Smolders et al., 2019). For example, the entry of microglial cells into the developing quail retina is related to extracellular ATP/ADP or UTP/UDP 
(Martin-Estebane et al., 2017). In this sense, intracellular $\mathrm{Ca}^{2+}$ waves, which are elicited by ATP and propagate from cell to cell, affect the migratory response of microglial cells (Sieger et al., 2012; Morales-Ropero et al., 2021), and might be involved in the colonization of the developing nervous tissue.

The microglial spreading finally results in their "tiled" distribution in the adult brain, in which each cell and their processes occupy their own spatial domain, not overlapping with other microglia. One of the proposed mechanisms contributing to the acquisition of this distribution is contact repulsion between individual microglia (Hammond et al., 2021).

\section{Heterogeneity of Microglia}

Microglia is not a homogeneous population (Doorn et al., 2015; Kana et al., 2019; Tan et al., 2020). While all microglial cells express core "microglial" genes, as Cx3cr1, P2ry12, or Tmem119, microglia from specific brain regions express other genes at different levels, e.g., cerebellar microglia show an increased expression of genes related to phagocytosis and clearance when compared to cortical microglia (Ayata et al., 2018).

The features of different populations of microglial cells can appear from an initially homogeneous population that develops into different cells depending on environmental cues. Alternatively, microglial precursors can be a heterogeneous population comprising different subtypes, each one with intrinsic features, that gives rise to particular microglial cells (Stratoulias et al., 2019). In the second case, the existence of different microglial populations could partially be due to the different origin of dissimilar cells (Tan et al., 2020). In line with this, at least one study determines that a subset of microglial cells has a particular origin in mice (De et al., 2018). The authors reveal the existence of two different subpopulations of microglia: a larger population of "canonical" microglia that did not express Hoxb8, and Hoxb8-expressing microglia (about $25 \%$ of adult microglia) that derive from YS precursors, seed the AGM and fetal liver, and enter the developing brain at E12.5, significantly later than nonHoxb8 microglia (De et al., 2018).

\section{Maintenance of the Microglial Population}

Once within the neuroepithelium, microglial precursors are influenced by factors relevant for the maturation and/or maintenance of the microglia population, as members of the transforming growth factor- $\beta$ (TGF- $\beta$ ) family (Butovsky et al., 2014; Bohlen et al., 2017), and acquire a "microglia signature", that include the expression of genes like Sall1, P2ry 12 and Tmem112 (Amici et al., 2017; Butovsky and Weiner, 2018; Bohlen et al., 2019).

To maintain the YS lineage in microglia as a self-autonomous population it would be required that they could maintain themselves without appreciable renewal from HSC. This can be achieved either by a proliferation of microglia, continuously replacing cells with ones of their own population, or by microglia being a long-lived population with a low proliferation rate. Initially, it was postulated that microglial cells were long-lived cells that could persist the entire lifespan of mice or humans (Fuger et al., 2017). However, a detailed study has revealed that their proliferation rate is higher than previously thought
(Askew et al., 2017): around $0.69 \%$ of the microglia population is embarked in proliferation in mice at each moment, implying that the entire microglial population is replaced in about 96 days (the estimated value in humans is around 2\%). Therefore, individual microglial cells frequently replicate, although the microglial population as a whole may be considered as longliving. Receptors like CSFR1 and IL-1R regulate the replication of microglia (Bruttger et al., 2015; Askew et al., 2017). The steady density of microglial cells is maintained during adult life by coordinating proliferation and cell death (Askew et al., 2017).

\section{Alternative Origins of Microglia in the Developing Brain}

Despite the results reported above, other data raise concern about the hypothesis that the YS would be the exclusive site of origin of microglia.

In $\mathrm{Vav}-\mathrm{Cre}^{+}$:dicer knock-out mice the intraembryonic hematopoiesis is impaired, while YS hematopoiesis is not affected (Fehrenbach et al., 2018). Although similar numbers of microglial cells are reported during the embryonic development in WT and $\mathrm{KO}$ animals, about $40 \%$ less myeloid cells are counted in $\mathrm{KO}$ mice at $\mathrm{P} 1$, suggesting that a part of the microglia population present in the brain at this age does not derive from YS. Presumably, all or at least part of the myeloid cells of non-YS origin observed at $\mathrm{P} 1$ in this report correspond to the perinatal wave of infiltrating monocytes that do not contribute to the microglia population at adulthood (Askew et al., 2017).

Other reports also indicate that microglial cells may also derive from non-YS cells. The injection in E6.5-E7.5 mice with a blocking antibody against CSFR1 depletes YS macrophages but leaves the population of circulating monocytes unaltered. This procedure results in the total lack of microglial cells until E14.5, but microglia partially repopulate the brain by E17.5 and similar microglia numbers are found in adult brains of control and treated mice (Squarzoni et al., 2014; Hoeffel et al., 2015). Therefore, the depletion of microglial cells in the developing CNS is compensated at the end of development by the progressive appearance of new microglial cells that perhaps are related to fetal monocytes and that adopt microglial characteristics in the brain parenchyma (Ginhoux and Guilliams, 2016; Chen et al., 2020). This fact might indicate a non-YS source of microglia.

As mentioned before, the CNS of PU.1 ${ }^{-/-}$mice are devoid of microglia. However, the microglial population in the spinal cord of PU.1 $1^{-/-}$mice can be reconstituted after transplantation of BM cells from WT mice into neonatal PU.1 $1^{-1-}$ pups. This indicates that non-YS cells can invade the CNS and acquire the characteristics of microglial cells (Beers et al., 2006). Another work (Bennett et al., 2018) reveals that intraperitoneal injection of BM cells from WT mice into P1 Csfr $1^{-1-}$ mice, which lack microglia, results in the appearance of engrafted Tmem119+ cells in the brain of the host without microglia.

In birds, most adult microglia apparently do not derive from YS precursors. When YS-derived fluorescence-labeled cells are injected into the circulation of chick embryos before the establishment of intraembryonic hematopoiesis, many ramified microglial cells of YS origin appear until hatching. However, only occasionally labeled microglia are observed in the brain of 
newly hatched birds and no fluorescence is observed in the brains of adult birds. On the contrary, abundantly labeled microglia are seen in adult brains when labeled BM cells from newly hatched birds were injected before the start of intraembryonic hematopoiesis (Garceau et al., 2015). These results suggest that in the chick brain macrophages/microglial cells are first produced from cells of YS origin, but that they are later replaced by cells of BM lineage.

Zebrafish microglial cells may have alternative origins. Genetic labeling of restricted areas at different time points revealed that microglia of embryonic/larval stages originated from the RBI (see "Brief Description of Hematopoiesis in Non-mammalian Vertebrates" section). In contrast, most adult microglia are produced from the VDA during the definitive hematopoiesis (Xu et al., 2015). Microglia produced during the definitive hematopoiesis, in contrast to embryonic microglia, depend on the expression of the transcription factor c-Myb (Ferrero et al., 2018).

Differences between the origin of microglia in the mouse and zebrafish may be due to interspecific differences, but also open the question if in mammals alternative sources of microglia exist that still have not been identified (Thion and Garel, 2017). In any case, the ontogeny of brain macrophages/microglia is likely to be more complex than currently assumed (Prinz et al., 2019) and could encompass several sources during development.

To summarize, the current consensus is that microglial cells originate from a cell lineage appearing in the YS from primitive myeloid precursors or EMP. Several studies, however, indicate that some microglia, in mice and other vertebrates, might have an alternative origin during development, without contradicting that a great part of the microglial population originates in the YS.

\section{MICROGLIA-LIKE CELLS (MLC)}

Myeloid cells enter the nervous parenchyma during the whole life span of an organism and some of them apparently transform into cells resembling microglia, the MLC. Despite their resemblance to microglia, they do not become true microglial cells, because they differ in origin, morphological and functional aspects.

Engraftment of myeloid cells in the nervous parenchyma depends on the capacity of blood-derived cells to enter into the CNS. The BBB limits and hampers the entry of blood cells and most soluble blood components into the nervous parenchyma (Wettschureck et al., 2019). Therefore, the BBB precludes a continuous replacement of microglial cells of embryonic origin by cells arising from the BM. Similarly, the MLC population is also maintained by local proliferation (Askew et al., 2017). The consequence is that both microglia and MLC establish a common "macrophage network" within the nervous parenchyma.

\section{Engraftment of Myeloid Cells in Healthy CNS}

Although several studies (Ajami et al., 2007, 2011) discard the hypothesis that BM-derived monocytes might be a source of microglia in the adult healthy brain, many others show occasional appearance of MLC related to circulating myeloid cells. For example, labeled amoeboid cells are detected in the corpus callosum of postnatal rats after intracellular marking of blood monocytes with colloidal carbon and they occasionally adopt a ramified, microglia-like morphology (Kaur et al., 2001).

The question if circulating cells could engraft in the CNS, was addressed using chimeric mice in which host myeloid cells were depleted by irradiation (usually 9-11 Gy) before transplantation of donor BM or blood circulating labeled cells (Soulet and Rivest, 2008). It should be noted that host microglial cells are resistant to radiation and, therefore, are not depleted. Various studies have revealed that cells of donor origin engraft in the nervous parenchyma several days after the transplant (e.g., Kennedy and Abkowitz, 1998), some of them acquiring a microglial morphology (Priller et al., 2001; Simard and Rivest, 2004; Xu et al., 2020). However, if the head of the recipient mouse is protected during irradiation, the brain shows no engraftment, while the unprotected spinal cord is infiltrated by numerous myeloid cells (Mildner et al., 2007). This raises the concern that the engraftment of cells observed after irradiation would not be a physiological event, because this procedure artificially enhances the engraftment of cells by perturbing the $\mathrm{BBB}$ and producing neuroinflammation. Moreover, the BM transplant probably releases HSC into the circulating blood, which in normal conditions would be restricted to the BM, and, therefore, would not be able to originate MLC (Larochelle et al., 2016).

In the parabiosis model (Ajami et al., 2007; Liu et al., 2007; Hashimoto et al., 2013) the blood circulation of two mice are surgically joined, so that the fate of the circulating cells of one of the two parabionts, for example expressing the green fluorescent protein (GFP), could be determined in the other GFP-negative mouse. This method avoids any alteration of the $\mathrm{BBB}$ and the artificial release of BM-residing HSC into the blood. However, as no myeloablation is carried out, precursors from each partner are supposed to compete with similar cells from the other animal, possibly resulting in an underestimation of the rate of engraftment. Under these conditions no (Ajami et al., 2007) or very low (Massengale et al., 2005) engraftment in the healthy brain is reported. In a modification (Ajami et al., 2011), one of the partners (the GFP-negative mouse) is irradiated to achieve myelodepletion, whereas the other one is protected. Although nearly $80 \%$ of GFP-positive circulating cells are found in the peripheral blood of the GFP-negative mouse, there is no noticeable colonization of the irradiated CNS by GFP-positive cells. This suggests that the engrafting cells in the traditional irradiation-BM transplantation model are HSC that are not released into the blood circulation in parabiosis.

Chemotherapeutic drugs such as busulfan have been used to deplete host myeloid cells avoiding the side effects of irradiation (Larochelle et al., 2016; Youshani et al., 2019). Even though the busulfan treatment results in high levels of chimerism in the peripheral blood, conflicting results about the efficiency of microglial engraftment after this treatment are reported. One study reports that far less MLC appear after busulfan treatment than in whole body irradiated chimeric mice (Kierdorf et al., 2013b). According to this 
work, busulfan induces less alteration of the BBB and less inflammation in the brain than irradiation. However, another report (Capotondo et al., 2012) indicates that more MLC of donor origin appear after busulfan immunodepletion than after irradiation. Similar regimens of irradiation (11 Gy) are used in both articles, but the busulfan treatments are different $(3 \times 30 \mathrm{mg} / \mathrm{kg}$ in Kierdorf et al., 2013b $)$ and $4 \times 25 \mathrm{mg} / \mathrm{kg}$ in Capotondo et al., 2012). It has been reported that busulfan at concentrations around $100 \mathrm{mg} / \mathrm{kg}$ produces an artificial engraftment of myeloid cells (Larochelle et al., 2016; Youshani et al., 2019), an amount reached by Capotondo et al. (2012) but not by Kierdorf et al. (2013b). This could in part explain the described differences. Interestingly, Capotondo et al. (2012) also report that treatment with a busulfan derivative (Triosulfan) unable to cross the BBB does not result in any appreciable engraftment of myeloid cells, suggesting that the engraftment into the brain tissue requires an effect of the myeloablative drug on the nervous parenchyma.

In summary, although the experimental procedures used to determine the entry of myeloid cells into the adult healthy CNS are likely to affect the recruitment of BM-derived microglia, the data strongly suggest that the mature microglial population is mostly permanent and autonomously self-renews with scarce contribution from peripheral BM-derived cells in the healthy brain (Figure 3A).

\section{Engraftment of Myeloid Cells in the Pathological CNS}

In contrast to physiological conditions, numerous cells of myeloid lineage appear in the nervous parenchyma in pathological situations such as in Alzheimer's disease models, experimental autoimmune encephalitis (EAE, the mouse model of multiple sclerosis), or traumatic injury. This implies that the diseased or preconditioned brain is in general far more receptive than the healthy brain to the entry of myeloid cells into the nervous parenchyma.

Some reports claim that the myeloid cells that penetrate the nervous parenchyma do not become microglial cells, but only give rise to macrophages that disappear after the end of the pathological situation and that the microgliosis observed in pathologies as facial nerve axotomy and EAE would be the only consequence of the expansion of resident microglia (Ajami et al., 2007, 2011). However, many publications indicate that at least some of the engrafted cells adopt microglial features in the parenchyma (Priller et al., 2001; Soulet and Rivest, 2008; Kierdorf et al., 2013b; Bennett et al., 2018). It has been shown that the engrafted myeloid cells persistently colonize the parenchyma for more than 30 weeks after a lipopolysaccharide (LPS) insult and acquire radio-resistance as well as many other traits of microglial cells, although they failed to adopt a complete microglial identity (Shemer et al., 2018).

Two facts seem to be decisive for the entrance of myeloid cells into the nervous parenchyma: (i) the permeability of the $\mathrm{BBB}$; and (ii) the previous presence of microglial cells. As later described, these facts are not independent but rather closely linked.

\section{Blood-Brain Barrier Permeability}

The $\mathrm{BBB}$ permeability is compromised in most pathological situations (Dinet et al., 2019; Thurgur and Pinteaux, 2019; Giannoni et al., 2020; Yu et al., 2020). This allows the passage of blood cells into the nervous parenchyma and is likely to be the reason why many engrafted cells appear in the diseased brain. Interestingly, the number of engrafted myeloid cells after busulfan treatment (with minimal alteration of the $\mathrm{BBB}$ ) is similar in the lesioned and contralateral sides of mice with facial nerve axotomy. However, far more myeloid cells of donor origin appear in the lesioned side than in the unlesioned one in irradiated mice (with altered BBB; Kierdorf et al., 2013b), reinforcing the idea that BBB integrity plays a decisive role in determining the entry of blood-derived cells into the parenchyma.

However, BBB leakiness is not the sole factor contributing to the entry of myeloid cells into the nervous parenchyma (Ajami et al., 2007), and additional signals from the diseased nervous parenchyma can promote the invasion of myeloid cells:

Several cytokines/chemokines produced in the injured brain alter the permeability of the $\mathrm{BBB}$, allowing the passage of substances and cells that are normally excluded from the brain parenchyma (Pan et al., 2011). Among the molecules that can be involved in the recruitment of BM cells into the nervous parenchyma are the chemokines CCL2 (MCP1), CX3CL1, and CXCL10 and adhesion molecules such as LFA-1, ICAM-1, VCAM-1, and E-selectin (Larochelle et al., 2016; Li et al., 2019). One of the main chemoattractants of myeloid cells is CCL2, which promotes the adhesion of blood monocytes and macrophages to the endothelial wall and subsequent infiltration to the brain parenchyma. This chemokine is released by numerous cells, including astrocytes, microglial cells, and neurons (Banisadr et al., 2005; Deshmane et al., 2009), and has been implicated in neuropathological situations (Reaux-Le Goazigo et al., 2013). In photodamaged retinas, macrophages and activated microglial cells produce the pro-inflammatory cytokine IL- $1 \beta$ that in turn promotes the expression of CCL2 (and other chemokines) by Müller cells and retinal pigment cells, associated with the accumulation of monocytes-macrophages in the damaged retina (Natoli et al., 2017). CCR2, the CCL2 receptor, seems to determine the recruitment of myeloid cells into the nervous parenchyma, as mice lacking this receptor show substantially less recruitment of myeloid cells than WT mice (Mildner et al., 2007; Lund et al., 2018). Interestingly, the development of microglia in the embryo does not depend on the CCL2/CCR2 system, as $\mathrm{Cr} 2^{-/-}$mice do not show different numbers of microglia than WT mice (Mildner et al., 2007).

\section{Microglia Depletion}

It has been proposed that monocyte-derived macrophage precursors compete with embryonic-derived macrophages to occupy the niche corresponding to each macrophage type (Guilliams and Scott, 2017; Guilliams et al., 2020). According to this idea, the previous presence of microglial cells in the parenchyma would limit the engraftment of myeloid cells into the nervous parenchyma. In the normal brain, microglial cells 


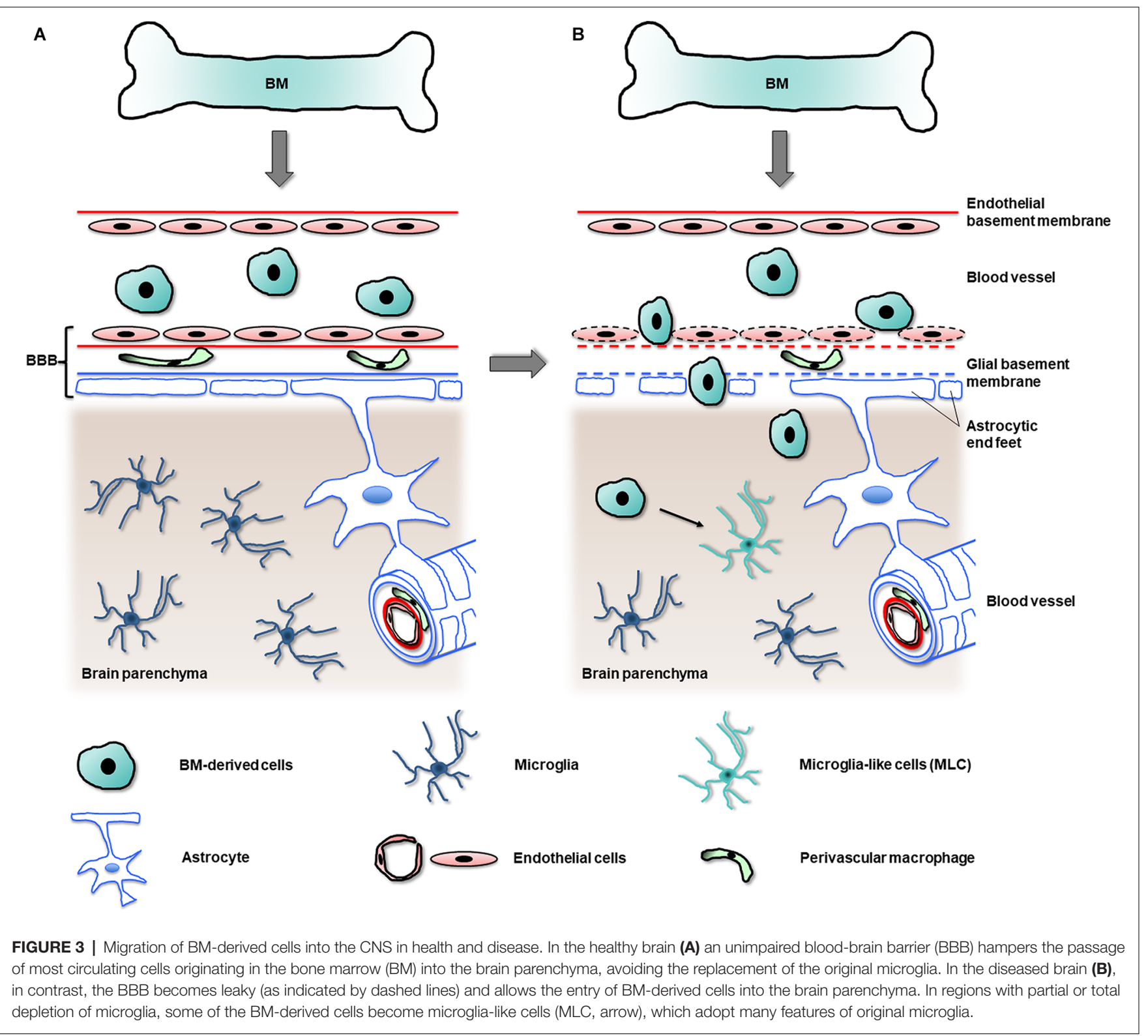

occupy entirely the "microglial niche" apparently hampering the engraftment of MLC. This would explain the scarcity of engraftment from BM-derived cells after irradiation because the radio-resistant original microglia are always present. However, the engraftment could take place if all or part of this niche was void, as it occurs in pathological situations. This idea has been addressed by depleting the microglial population.

Genetic depletion of microglia (Green et al., 2020) can be achieved by using animals lacking essential genes for the development or maintenance of microglia, such as Sfpi1 and Csf1r. A detailed study using Csf1r $r^{-/-}$mice shows the nearly total absence of microglia during the development (Erblich et al., 2011). However, disparate results are obtained in adult mice depending on the brain region: while microglia depletion is nearly complete (99\%) in the thalamus and hypothalamus, it reaches only $65 \%$ in the piriform cortex. It has to be taken into account that the expression of these genes is not specific to microglial cells and can affect numerous organs, making it difficult to distinguish between the direct effects of the lack of microglia and those due to indirect effects on microglia due to the alteration of other organs and the hematopoietic system (Waisman et al., 2015). Recently, it has been found that mice without $f m s$-intronic regulatory element (FIRE) enhancer of Csf1r expression lack microglia and resident macrophages in several organs, such as skin and kidney, but have normal myeloid populations in the peripheral blood, representing a useful model of genetic depletion of microglia without disturbing blood leukocytes (Rojo et al., 2019).

To establish models to eliminate microglial cells in vivo with fewer effects on the entire organism, conditional and pharmacological methods have been developed. For the conditional depletion of microglia, the expression 
of a suicide gene [such as herpesvirus thymidine kinase (HVTK) or the diphtheria toxin receptor (DTR)] is limited to macrophage/microglial cells in transgenic mice. The death of the cells expressing the suicide gene is triggered by the administration of a toxin (ganciclovir or diphtheria toxin, respectively) at defined times. These methods can eliminate around $90 \%$ of microglial cells (Waisman et al., 2015).

Most pharmacological methods to deplete microglia rely on CSFR1 inhibitors because the ligands of this receptor are needed for the maintenance of microglial cells (Erblich et al., 2011; Keshvari et al., 2021). CSFR1 inhibitors PLX3397 or PLX5622 deplete up to 99\% of the microglial cells (Elmore et al., 2014; Huang et al., 2018b; Green et al., 2020). Usually, it is assumed that this treatment does not affect the myeloid and lymphoid compartments of blood and BM. However, this idea has recently been questioned, showing that PLX5622 treatment caused long-term effects on hematopoietic cells in BM and on BM-derived macrophages (Lei et al., 2020). This observation must be considered when interpreting data from animals treated with CSFR1 inhibitors, as CNS engraftment of blood cells might be perturbed by the treatment.

The microglial population recovers around 7 days after the end of the treatment (Elmore et al., 2014; Bruttger et al., 2015; Huang et al., 2018b). What is the origin of the cells which repopulate the microglial compartment? Most authors support the idea that the microglial population recovers from cells resident in the CNS (Elmore et al., 2014; Huang et al., 2018b). In this sense, mice in which microglia are depleted with PLX5622 and irradiated with head covering (and therefore with a minor alteration of the BBB) have minimal engraftment of $\mathrm{BM}$-derived cells and the brain is repopulated by endogenous microglia. On the contrary, when the head covering is omitted and the BBB is likely to be affected, there is a robust engraftment of BM-derived cells, which participate in the repopulation (Cronk et al., 2018). This suggests that repopulating microglia are of intrinsic origin, without large participation of cells of BM origin unless the BBB would be affected (Bruttger et al., 2015; Zhan et al., 2019).

Originally, it was proposed that the repopulating cells derived from the proliferation of microglia precursors in the brain and were characterized by the expression of nestin (Elmore et al., 2014). Other authors using genetically labeled cells affirm that new microglial cells result from the proliferation of the scarce microglial cells (around 1\%) remaining after the depletion (Huang et al., 2018b). They also state that the expression of nestin is not linked to a subgroup of microglial cells, but rather transiently found in all proliferating microglia and in myeloid cells outside the CNS. Similar conclusions are drawn in a study using DTR mice (Bruttger et al., 2015), which moreover indicates the presence of clusters of proliferating microglia in the brain that disappear after reaching the normal density of microglia. A study combining depletion of microglia and labeling of proliferating cells (Zhan et al., 2019) reinforces the idea that nestin expression is a transient marker of immature microglia and not a marker of microglial precursors.

The retina is a suitable region to study the effect of local depletion of microglia. According to Huang et al. (Huang et al., 2018a), PLX5622 treatment eliminated all retinal microglia, impeding the repopulation from remaining microglial cells in the retina. In this case, the repopulating cells derive from the proliferation and migration of residual microglia in the optic nerve and from macrophages from the ciliary body or iris (cells of BM origin). Local depletion of microglia occurs in some pathologies of the retina. For instance, after light damage of the retina, resident microglia leave the inner regions of the retina and migrate towards the photoreceptor cell layer (Santos et al., 2010; O'Koren et al., 2019). The vacant space left by migrating cells is occupied by cells coming from other regions of the CNS or by monocyte-macrophages from the ciliary body or iris (Huang et al., 2018a; Zhang et al., 2018; McPherson et al., 2019). Interestingly, a study combining microglial depletion and retinal injury shows that monocytes entering the retina after injury are resistant to CSFR1 inhibition, while cells repopulating the retina in uninjured retinas remain sensitive to the same inhibitor (Paschalis et al., 2018). These results suggest that different progenitors of microglia or MLC occupy the microglial niche in healthy and pathological nervous tissue.

A recent report (Xu et al., 2020) indicates that more than $90 \%$ of the microglial population is replaced by MLC of BM origin when original microglia have been depleted before myeloablative irradiation and inoculation of BM cells. In line with this, Cronk et al. (2018) report that persistent partial depletion of microglia induces the engraftment of blood circulating myeloid cells into the nervous parenchyma. In another model that combines microglia depletion with irradiation of head-protected mice or busulfan treatment and BM transplant (Lund et al., 2018), the microglial population consists of a mixture of "bona fide" microglia and MLC derived from circulating leukocytes. Therefore, BM-derived cells may significantly participate in the recovery of the microglial population when the microglial niche is not occupied without the need for apparent disturbance of the $\mathrm{BBB}$.

How can microglia depletion affect the colonization and engraftment of circulating cells? Beforehand, we must consider that the elimination of microglial cells is not a physiological event, but it is likely that it alters the normal CNS environment. Some authors defend that microglia depletion does not induce great changes in CNS cells or cytokine release (Parkhurst et al., 2013; Elmore et al., 2014), but others describe an increase of pro-inflammatory cytokines (Bruttger et al., 2015; Lund et al., 2018). As reported above, the release of cytokines/chemokines affects the entry and engraftment of BM-derived cells into the CNS, because of the chemotactic attraction of circulating cells and a BBB compromise. Therefore, the absence of microglia might induce increasing levels of cytokines/chemokines and other molecules, such as ROS, that in turn might condition the colonization of the CNS parenchyma by hematogenous cells (da Fonseca et al., 2014).

In addition, microglia depletion can directly affect the integrity of the $\mathrm{BBB}$, as microglia contribute to the closure of small openings in the BBB produced during the normal replacement of endothelial cells or in pathological situations (Lou et al., 2016; Taylor et al., 2018). Hence, the absence of microglia 
would result in more openings in the BBB and increased access to the nervous parenchyma.

Recently, it has been shown that activated microglia probably interfere with entry, proliferation, survival, and/or migration of infiltrating macrophages at the level of the spinal cord, as depletion of microglia results in a larger proportion of macrophages at the lesion and their spreading to other regions of the nervous parenchyma (Plemel et al., 2020). The authors propose that microglia could affect the infiltration of macrophages either directly by secreting factors affecting the macrophage dynamics (as IGF-1), or indirectly by protecting the extracellular matrix (for example microglial cells produce protease inhibitors) and/or by protecting and repairing the $\mathrm{BBB}$ (as described above).

From all those studies, it emerges that the entry of myeloid cells to the nervous parenchyma is related to a functional alteration of the BBB. Some of the myeloid cells that enter would give rise to long-lasting MLC depending on the presence of resident microglia. In the absence of microglia, i.e., in an "empty microglial niche", part of the myeloid cells would give rise to MLC. Once in the CNS, MLC would proliferate and maintain as an autonomous population, as described in section "Maintenance of the Microglial Population" for original microglia (Figure 3B). However, the engraftment of BM-derived cells, when the microglial niche is not occupied and the BBB is apparently unaltered, opens the question of the relative importance and interrelation between these two factors.

\section{DEVELOPMENT OF THE MICROGLIA/MICROGLIA-LIKE IDENTITY}

Although microglia are supposed to be the tissue-resident macrophages of the nervous parenchyma, they are considered apart from other macrophages because of their origin and maintenance. Microglial cells are assumed to originate and populate the nervous tissue before the closure of $\mathrm{BBB}$ that isolates them from the rest of the embryo at a time when only YS precursors are available. In contrast, most other tissueresident macrophages derive from fetal monocytes, while in some organs, like the dermis and gut, they are continuously replaced by monocytes derived from BM (Sheng et al., 2015; MarquezRopero et al., 2020).

Interestingly, transplantation of different types of macrophages (from YS, from fetal liver, or from mature monocytes) reconstitutes alveolar macrophages in mice lacking this population, suggesting that the precursors adopt the features of the macrophage-resident cells of the environment where they were located (van de Laar et al., 2016). Similar observations lead to the assumption that signals issued from the local environment would shape the immunophenotypic and functional features of resident macrophages (Guilliams and Scott, 2017; Bleriot et al., 2020; Guilliams et al., 2020).

Nevertheless, the case of microglia is apparently different, as "true microglial cells" are only produced from YS progenitors, whereas BM-derived progenitors give rise to MLC, which do not adopt a complete microglial identity in a neural microenvironment (Bruttger et al., 2015; Bennett et al., 2018;
Cronk et al., 2018; Shemer et al., 2018). Accordingly, BM cells engrafting the CNS undergo morphological (e.g., they adopt a morphology like the original microglia and acquire radioresistance) and molecular modifications (e.g., they partially adopt the epigenetic landscape of microglia). They share around $90 \%$ of their transcriptome with host microglia, including the expression of some key microglial genes such as Tgbr2, encoding the receptor of TGF- $\beta$. However, they remain transcriptionally different from original microglia, as they show a reduced expression of some mRNAs highly expressed in mature microglia, such as Tmem 119 and P2yr12, and do not express the transcriptional regulator Sall1 (Shemer et al., 2018).

\section{Environmental and Intrinsic Traits Shaping the Microglia/Microglia-Like Identity}

Early work has already revealed the importance of the environment for the acquisition of microglial features: Isolated microglia cultured on an astrocyte layer (to mimic a neural environment) adopt a ramified morphology in contrast to the amoeboid morphology shown by microglial cells in standard culture conditions (Sievers et al., 1994). More recent observations corroborate that factors released by astrocytes promoted the survival and morphological differentiation of microglial cells (Schilling et al., 2001; Bohlen et al., 2017). On the contrary, isolated microglia cultured in a "non-neural" medium reduce the expression of microglial signature genes (as Tmem119 and P2ry12), although they recover their entire microglial identity if transplanted to a brain lacking microglia (Bohlen et al., 2017). in vivo experiments also support the relevance of the neural environment for the acquisition of the "microglial identity": Isolated microglial cells of YS origin transplanted to the brain of a Csf1r ${ }^{-/-}$mouse (lacking microglia) produced true microglia (Bennett et al., 2018).

Evidently, if the neural environment were the only factor determining the development of microglia features, it could be expected that any precursor placed in the brain would become microglia. However, the aforementioned authors (Bennett et al., 2018) report that BM-derived cells transplanted into brains lacking microglia originate MLC instead of giving rise to true microglia, as they do not express key signature genes of true microglia, like Sall1. Comparable results have been reported elsewhere (Cronk et al., 2018; Lund et al., 2018; Shemer et al., 2018), indicating that the ability to give rise to "true microglia" seems to be restricted to YS-derived precursors. Indeed, YS-derived embryonic macrophages (EM) and BM-derived macrophages (BMDM) co-cultured with neural stem/progenitor cells show clear differences. While EM differentiates to microglial cells which express Tmem 119 mRNA, a marker for microglia with advanced or total differentiation (Bennett et al., 2016), BMDM cultured in the same conditions do not express Tmem 119 at noticeable levels, although they adopt a microglia-like morphology and are positive for Iba-1 (Yosef et al., 2018). Therefore, the acquisition of the microglial identity depends on both cell intrinsic and environmental factors (Bennett et al., 2018).

Apparently, the embryonic experience of YS precursors shapes the features of true microglia required for the CNS 
development, while MLC precursors, that act when the CNS is already developed, do not maintain these features, and lose some of the characteristics of true microglia. Many of the "signature genes" of YS-derived microglia are regulated by the transcription factor Sall1 (Guilliams et al., 2020), and, therefore, the expression of the Sall1 gene is likely to play a key role in establishing the microglial identity (Buttgereit et al., 2016; Lund et al., 2018; Shemer et al., 2018). Different hypotheses have been proposed to explain why MLC derived from BM do not express key microglial genes, even though the neural environment induces the expression of other "microglial" genes. Thus, it has been suggested that chromatin accessibility in BM-derived cells precludes the expression of Sall1 or that a specific signal in the embryonic brain is needed to induce Sall1 expression (Guilliams et al., 2020).

A recent report (Chen et al., 2020) reveals that fetal monocytes enter the brain parenchyma during development and after a neonatal stroke. Once in the parenchyma, they progressively adopt a microglial identity, expressing microglial signature genes including Sall1. The authors conclude that fetal CCR2+ monocytes (originated from fetal liver hematopoiesis) might contribute to true microglia in the mouse brain. Therefore, the ability to originate true microglial cells would not be exclusive to cells produced directly in the YS. Rather this capacity could progressively be lost during the development of the hematopoietic system, as fetal monocytes, but not adult ones, maintain it.

The identity of the precursors of true microglia has been already discussed in section "Microglial Origin From the Yolk Sac". MLC may derive either from immature hematopoietic precursors or from circulating monocytes. In relationship with the monocyte origin, at least two monocyte populations have been described in the circulating blood of mice: $\mathrm{Ly}-6 \mathrm{C}^{\text {low }}$ $\left(\mathrm{CCR} 2^{-}\right.$and CX3CR1 ${ }^{\text {hi }}$ ) and Ly-6C ${ }^{\text {hi }}\left(\mathrm{CCR} 2^{+}\right.$and CX3CR $\left.1^{\text {low }}\right)$. The latter one is thought to originate MLC (Mildner et al., 2007; Lund et al., 2018).

These results do not discard the possibility that BM-derived HSC would be involved in the production of MLC. Although low numbers of HSC are present in the circulating blood in healthy conditions (Schreier and Triampo, 2020), inflammatory stimuli elicit the increased mobilization of HSC from the BM to the blood (Ratajczak et al., 2018). Thus, the increased number of engrafted myeloid cells observed in the diseased brain might relate to the higher number of immature hematopoietic precursors present in the peripheral blood in pathological conditions. In fact, a study claims that the ability to generate MLC is restricted to uncommitted HSC or progenitor cells from the BM (Ajami et al., 2011).

Highlighting the relevance of hematopoietic precursors in the production of MLC, it has been reported that they replace around $92 \%$ of the original microglia in the brain when BM cells are transplanted to irradiated and microgliadepleted mice. However, this rate is reduced to around $80 \%$ after peripheral blood transplantation ( $\mathrm{Xu}$ et al., 2020). It is likely that more HSC are present in the BM transplant than in the peripheral blood transplant, and this could result in a larger rate of replacement. Associated with that is the surprising observation that transplantation of a single HSC from $\mathrm{BM}$ gives rise to a comparable engraftment of myeloid cells in the CNS as transplanting $10^{6}$ cells from the whole BM (Massengale et al., 2005).

In summary, the acquisition of a microglial identity depends on different factors. One of them is the neural environment; the other one is the intrinsic characteristics of the cells, as only hematopoietic cells from the embryo seem to be able to produce true microglia, whereas adult hematopoietic cells originate MLC.

\section{Functional Differences Between Microglia and MLC}

Despite that MLC resemble microglia in morphology and in the expression of many markers, they respond to injury differently (Bennett et al., 2018). Although both cell types actively move toward injured areas of the brain, MLC move faster towards a laser burn than microglia and MLC do not change their ramification in response to an intraperitoneal LPS injection, while microglia do. In addition, many genes were differentially expressed in microglia and MLC after LPS treatment. For example, transcripts encoding the scavenger receptor Marco are induced in microglia but not in engrafted cells (Cronk et al., 2018; Shemer et al., 2018), indicating that microglia of embryonic origin and MLC are not totally equivalent. In fact, BM-derived cells seem to be more efficient than YS-derived microglia in particular tasks, mostly associated with aging, such as phagocytosis of amyloid deposits or debris generated during senescence (Shemer et al., 2018; Li et al., 2020). In this sense, it is well known that both microglia and macrophages of blood origin fulfill different roles after a brain injury (Amici et al., 2017; MesquidaVeny et al., 2021). However, to our knowledge, the functional differences between microglia and MLC are not well established, for example, if they have similar functions in parenchyma surveillance, sculpting of nerve projections, and synaptic pruning.

There are reports suggesting that microglia and $\mathrm{BM}$ macrophages are very similar. During the acute phase of EAE, microglia downregulate some of the microglial-specific genes (Butovsky et al., 2014; Jordao et al., 2019; Grassivaro et al., 2020), resulting in RNA levels similar to infiltrating macrophages in the same phase. Additionally, mRNA expression of some of the microglial genes is transiently enhanced in macrophages of $\mathrm{BM}$ origin during the chronic phase of EAE (Grassivaro et al., 2020). This has led the authors to propose that microglia and macrophages of BM origin phenotypically converge after a brain injury to act as a single functional unit and that therefore both cell types might not be contemplated as totally different entities (Grassivaro et al., 2020).

In any case, BM cells invading the nervous parenchyma look and act like microglia, although they cannot be considered as true or "bona fide" microglia (McPherson et al., 2019). For example, no behavioral effects are observed in mice with a significant replacement of microglia by engrafted cells of BM origin (Cronk et al., 2018), suggesting that the level of microglia replacement does not affect brain function. 


\section{HUMAN vs. MOUSE MICROGLIA}

The former discussion has focused on microglia and MLC in the murine brain. However, for therapeutic purposes, we need to increase our knowledge of microglia and MLC in the human brain. Several studies have dealt with human microglia and their similarities to mouse microglia (Menassa and Gomez-Nicola, 2018; Masuda et al., 2020; Zia et al., 2020). A gene expression study of microglia in 10 different species (Geirsdottir et al., 2019) reveals that human microglia show a larger heterogeneity than murine ones. This can be related to the fact that more pathological events occur in the human brain than in the brain of other species because of their longer life span. These events presumably produce the development of particular subsets of microglia (Keren-Shaul et al., 2017; Masuda et al., 2020) and more frequent myeloid cell engraftment. Therefore, an appreciable number of MLC is supposed to be present in the brain of long-lived organisms, such as humans, because of the repeated production of pathological events (often with only subclinical effects) that are frequently associated with local disruption of BBB and limited depletion of microglia.

Recently, it has been reported that the stromal fraction of human BM contains a $\mathrm{CD} 45^{-} \mathrm{CD}_{11 \mathrm{~b}^{+}}$precursor, apparently devoted to producing cells labeled with Iba-1 and expressing genes of developing (as RUNX1,SPF1, and CSF1R) and adult human microglia (including P2RY12, TMEM119, and ITGAM). Moreover, cells produced from these precursors show increased phagocytic capacity, are activated in response to LPS, and integrate into human brain tissue, conserving the expression of TMEM119 marker (Bruzelius et al., 2021). Therefore, it seems that human BM cells might be able to give rise to new microglia. To our knowledge, a similar precursor in the mouse BM has not been reported until now.

\section{DISCUSSION AND CONCLUSIONS}

While the original microglia in mammals mostly derive from non-replaced embryonic precursors of YS origin, the first macrophages and/or microglia appearing during development in zebrafish and chicken are replaced by cells derived from intraembryonic or definitive hematopoiesis (Garceau et al., 2015; Ferrero et al., 2021). The persistence of the original microglia in mammals may reflect a greater isolation of the nervous parenchyma precluding the entry of new microglial precursors. This would account for differences in microglia between mammals and other groups. In fact, analysis of the microglial gene expression reveals that zebrafish and chicken microglia show an expression pattern that situates them out of the mammalian group (Geirsdottir et al., 2019).

In contrast to homeostatic conditions, different events affecting the CNS allow large engraftment of BM-derived cells in the brain parenchyma. This change is apparently related to the presence of an empty microglial niche and the accessibility of precursors to the parenchyma because of the alteration of BBB permeability. The acquisition of microglial features might depend on: (a) intrinsic properties of the precursors because only cells deriving from the YS give rise to "true microglial cells", while BM-derived cells are only able to give rise to MLC; and (b) local cues, as conditions mimicking a nervous system environment-for example co-cultures with astrocytes or neurons, astrocyte conditioned medium - are needed to acquire microglial (or MLC) characteristics.

Therefore, the microglial compartment of the mammalian adult brain integrates two different components: "true microglial cells" and MLC. Whereas the first one is of embryonic origin, MLC are myeloid cells of BM origin that engraft the brain in relationship with the depletion of the original microglia and/or when the BBB is compromised. Consequently, MLC likely integrate into the original network of microglia of embryonic origin and could carry out similar functions.

The topic discussed in this review is relevant to the development of therapeutic strategies in diseases in which microglial cells are involved (Bennett and Bennett, 2020; Xu et al., 2020), such as neurological/psychiatric disorders like autism spectrum disorders and compulsive behavior, ischemia, neurodegeneration, and traumatic injury. There is strong evidence that original microglia of embryonic origin can be replaced by myeloid cells of $\mathrm{BM}$ origin in the human brain, similar to the findings in the mouse CNS (Menassa and GomezNicola, 2018; Zia et al., 2020). This can represent a scientific basis to use myeloid transplants to treat CNS diseases with defective microglia, as neuropathologies developing in aged people when microglia is dysfunctional ( $\mathrm{Ng}$ et al., 2021), or some forms of leukoencephalopathies in which CSFR-1 is deficient and microglial phenotype is altered (Kempthorne et al., 2020). In these cases, transplants would replace toxic or noxious microglia with healthy cells able to restore homeostasis. However, extensive depletion of the microglial niche might be necessary to replace these defective microglia. Thus, future experiments have to establish optimal conditions and procedures to achieve this goal.

\section{AUTHOR CONTRIBUTIONS}

MAC designed the manuscript, wrote the first draft and participated in editing. MRS, DM-O, and JLM-T contributed to the editing and writing of the final version. VEN edited the manuscript and prepared the figures. All authors contributed to the article and approved the submitted version.

\section{FUNDING}

During the time of preparation of this review, the authors received funding from the University of Granada, Spain, and FEDER-Junta de Andalucía, Spain (grant number A1-CTS-324UGR18).

\section{ACKNOWLEDGMENTS}

We want to thank all people for fighting in the front line of the COVID-19 pandemic, during which most parts of this article was written. We also acknowledge the task of the reviewers who contributed to improve the quality of this article. 


\section{REFERENCES}

Ajami, B., Bennett, J. L., Krieger, C., McNagny, K. M., and Rossi, F. M. (2011). Infiltrating monocytes trigger EAE progression, but do not contribute to the resident microglia pool. Nat. Neurosci. 14, 1142-1149. doi: 10.1038/ nn. 2887

Ajami, B., Bennett, J. L., Krieger, C., Tetzlaff, W., and Rossi, F. M. (2007). Local self-renewal can sustain CNS microglia maintenance and function throughout adult life. Nat. Neurosci. 10, 1538-1543. doi: 10.1038/ nn2014

Alliot, F., Godin, I., and Pessac, B. (1999). Microglia derive from progenitors, originating from the yolk sac and which proliferate in the brain. Brain Res. Dev. Brain Res. 117, 145-152. doi: 10.1016/s0165-3806(99)00113-3

Amici, S. A., Dong, J., and Guerau-de-Arellano, M. (2017). Molecular mechanisms modulating the phenotype of macrophages and microglia. Front. Immunol. 8:1520. doi: 10.3389/fimmu.2017.01520

Andjelkovic, A. V., Nikolic, B., Pachter, J. S., and Zecevic, N. (1998). Macrophages/microglial cells in human central nervous system during development: an immunohistochemical study. Brain Res. 814, 13-25. doi: 10.1016/s0006-8993(98)00830-0

Angelim, M., Maia, L., Mouffle, C., Ginhoux, F., Low, D., Amancio-DosSantos, A., et al. (2018). Embryonic macrophages and microglia ablation alter the development of dorsal root ganglion sensory neurons in mouse embryos. Glia 66, 2470-2486. doi: 10.1002/glia.23499

Ashwell, K. (1991). The distribution of microglia and cell death in the fetal rat forebrain. Brain Res. Dev. Brain Res. 58, 1-12. doi: 10.1016/01653806(91)90231-7

Askew, K., Li, K., Olmos-Alonso, A., Garcia-Moreno, F., Liang, Y., Richardson, P., et al. (2017). Coupled proliferation and apoptosis maintain the rapid turnover of microglia in the adult brain. Cell Rep. 18, 391-405. doi: 10.1016/j.celrep.2016. 12.041

Ayata, P., Badimon, A., Strasburger, H. J., Duff, M. K., Montgomery, S. E., Loh, Y. E., et al. (2018). Epigenetic regulation of brain region-specific microglia clearance activity. Nat. Neurosci. 21, 1049-1060. doi: 10.1038/s41593-0180192-3

Banisadr, G., Gosselin, R. D., Mechighel, P., Kitabgi, P., Rostene, W., and Parsadaniantz, S. M. (2005). Highly regionalized neuronal expression of monocyte chemoattractant protein-1 (MCP-1/CCL2) in rat brain: evidence for its colocalization with neurotransmitters and neuropeptides. J. Comp. Neurol. 489, 275-292. doi: 10.1002/cne.20598

Beers, D. R., Henkel, J. S., Xiao, Q., Zhao, W., Wang, J., Yen, A. A., et al. (2006). Wild-type microglia extend survival in PU.1 knockout mice with familial amyotrophic lateral sclerosis. Proc. Natl. Acad. Sci. U S A 103, 16021-16026. doi: $10.1073 /$ pnas.0607423103

Bennett, F. C., Bennett, M. L., Yaqoob, F., Mulinyawe, S. B., Grant, G. A., Hayden Gephart, M., et al. (2018). A combination of ontogeny and CNS environment establishes microglial identity. Neuron 98, 1170-1183.e8. doi: 10.1016/j.neuron. 2018.05.014

Bennett, M. L., and Bennett, F. C. (2020). The influence of environment and origin on brain resident macrophages and implications for therapy. Nat. Neurosci. 23, 157-166. doi: 10.1038/s41593-019-0545-6

Bennett, M. L., Bennett, F. C., Liddelow, S. A., Ajami, B., Zamanian, J. L., Fernhoff, N. B., et al. (2016). New tools for studying microglia in the mouse and human CNS. Proc. Natl. Acad. Sci. U S A 113, E1738-E1746. doi: 10.1073/pnas. 1525528113

Bertrand, J. Y., Kim, A. D., Violette, E. P., Stachura, D. L., Cisson, J. L., and Traver, D. (2007). Definitive hematopoiesis initiates through a committed erythromyeloid progenitor in the zebrafish embryo. Development 134, 4147-4156. doi: 10.1242/dev.012385

Bertrand, J. Y., and Traver, D. (2009). Hematopoietic cell development in the zebrafish embryo. Curr. Opin. Hematol. 16, 243-248. doi: 10.1097/MOH. 0b013e32832c05e4

Bian, Z., Gong, Y., Huang, T., Lee, C. Z. W., Bian, L., Bai, Z., et al. (2020). Deciphering human macrophage development at single-cell resolution. Nature 582, 571-576. doi: 10.1038/s41586-020-2316-7

Bleriot, C., Chakarov, S., and Ginhoux, F. (2020). Determinants of resident tissue macrophage identity and function. Immunity 52, 957-970. doi: 10.1016/j. immuni.2020.05.014
Bohlen, C. J., Bennett, F. C., Tucker, A. F., Collins, H. Y., Mulinyawe, S. B., and Barres, B. A. (2017). Diverse requirements for microglial survival, specification and function revealed by defined-medium cultures. Neuron 94, 759-773.e8. doi: 10.1016/j.neuron.2017.04.043

Bohlen, C. J., Friedman, B. A., Dejanovic, B., and Sheng, M. (2019). Microglia in brain development, homeostasis and neurodegeneration. Annu. Rev. Genet. 53, 263-288. doi: 10.1146/annurev-genet-112618-043515

Bruttger, J., Karram, K., Wortge, S., Regen, T., Marini, F., Hoppmann, N., et al. (2015). Genetic cell ablation reveals clusters of local self-renewing microglia in the mammalian central nervous system. Immunity 43, 92-106. doi: 10.1016/j. immuni.2015.06.012

Bruzelius, A., Hidalgo, I., Boza-Serrano, A., Hjelmer, A. G., Tison, A., Deierborg, T., et al. (2021). The human bone marrow harbors a CD45$\mathrm{CD}_{11 \mathrm{~B}^{+}}$cell progenitor permitting rapid microglia-like cell derivative approaches. Stem Cells Transl. Med. 10, 582-597. doi: 10.1002/sctm. 20-0127

Butovsky, O., Jedrychowski, M. P., Moore, C. S., Cialic, R., Lanser, A. J., Gabriely, G., et al. (2014). Identification of a unique TGF-beta-dependent molecular and functional signature in microglia. Nat. Neurosci. 17, 131-143. doi: 10.1038/nn.3599

Butovsky, O., and Weiner, H. L. (2018). Microglial signatures and their role in health and disease. Nat. Rev. Neurosci 19, 622-635. doi: 10.1038/s41583-0180057-5

Buttgereit, A., Lelios, I., Yu, X., Vrohlings, M., Krakoski, N. R., Gautier, E. L., et al. (2016). Sall1 is a transcriptional regulator defining microglia identity and function. Nat. Immunol. 17, 1397-1406. doi: 10.1038/ ni. 3585

Capotondo, A., Milazzo, R., Politi, L. S., Quattrini, A., Palini, A., Plati, T., et al. (2012). Brain conditioning is instrumental for successful microglia reconstitution following hematopoietic stem cell transplantation. Proc. Natl. Acad. Sci. U S A 109, 15018-15023. doi: 10.1073/pnas.12058 58109

Casano, A. M., Albert, M., and Peri, F. (2016). Developmental apoptosis mediates entry and positioning of microglia in the zebrafish brain. Cell Rep. 16, 897-906 doi: 10.1016/j.celrep.2016.06.033

Casano, A. M., and Peri, F. (2015). Microglia: multitasking specialists of the brain. Dev. Cell 32, 469-477. doi: 10.1016/j.devcel.2015.01.018

Chen, H. R., Sun, Y. Y., Chen, C. W., Kuo, Y. M., Kuan, I. S., Tiger Li, Z. R., et al. (2020). Fate mapping via CCR2-CreER mice reveals monocyte-tomicroglia transition in development and neonatal stroke. Sci. Adv. 6:eabb2119. doi: 10.1126/sciadv.abb2119

Cronk, J. C., Filiano, A. J., Louveau, A., Marin, I., Marsh, R., Ji, E., et al. (2018). Peripherally derived macrophages can engraft the brain independent of irradiation and maintain an identity distinct from microglia. J. Exp. Med. 215, 1627-1647. doi: 10.1084/jem.20180247

Cuadros, M. A., Garcia-Martin, M., Martin, C., and Rios, A. (1991). Haemopoietic phagocytes in the early differentiating avian retina. J. Anat. 177, $145-158$.

Cuadros, M. A., Martin, C., Coltey, P., Almendros, A., and Navascues, J. (1993). First appearance, distribution and origin of macrophages in the early development of the avian central nervous system. J. Comp. Neurol. 330, 113-129. doi: 10.1002/cne.903300110

Cuadros, M. A., and Navascues, J. (1998). The origin and differentiation of microglial cells during development. Prog. Neurobiol. 56, 173-189. doi: 10.1016/s0301-0082(98)00035-5

da Fonseca, A.C., Matias, D., Garcia, C., Amaral, R., Geraldo, L.H., Freitas, C., et al. (2014). The impact of microglial activation on blood-brain barrier in brain diseases. Front. Cell Neurosci. 8:362. doi: 10.3389/fncel.2014.00362

Daneman, R., Zhou, L., Kebede, A. A., and Barres, B. A. (2010). Pericytes are required for blood-brain barrier integrity during embryogenesis. Nature 468, 562-566. doi: 10.1038/nature09513

De, S., Van Deren, D., Peden, E., Hockin, M., Boulet, A., Titen, S., et al. (2018). Two distinct ontogenies confer heterogeneity to mouse brain microglia Development 145:dev152306. doi: 10.1242/dev.152306

Deczkowska, A., Keren-Shaul, H., Weiner, A., Colonna, M., Schwartz, M., and Amit, I. (2018). Disease-associated microglia: a universal immune sensor of neurodegeneration. Cell 173, 1073-1081. doi: 10.1016/j.cell.2018. 05.003 
del Rio-Hortega, P. (1919). El "tercer elemento" de los centros nerviosos. III. Naturaleza probable de la microglía. Bol. Soc. Esp. Biol. VIII, 108-115.

del Rio-Hortega, P. (1932). "Microglia," in Cytology and Cellular Pathology of the Nervous System, ed W. Penfield (New York: Hoeber), 483-534.

Deshmane, S. L., Kremlev, S., Amini, S., and Sawaya, B. E. (2009). Monocyte chemoattractant protein-1 (MCP-1): an overview. J. Interferon Cytokine Res. 29, 313-326. doi: 10.1089/jir.2008.0027

Dinet, V., Petry, K. G., and Badaut, J. (2019). Brain-immune interactions and neuroinflammation after traumatic brain injury. Front. Neurosci. 13:1178. doi: 10.3389/fnins.2019.01178

Doorn, K. J., Breve, J. J., Drukarch, B., Boddeke, H. W., Huitinga, I., Lucassen, P. J., et al. (2015). Brain region-specific gene expression profiles in freshly isolated rat microglia. Front. Cell Neurosci. 9:84. doi: 10.3389/fncel.2015.00084

Easley-Neal, C., Foreman, O., Sharma, N., Zarrin, A. A., and Weimer, R. M. (2019). CSF1R ligands IL-34 and CSF1 are differentially required for microglia development and maintenance in White and Gray matter brain regions. Front. Immunol. 10:2199. doi: 10.3389/fimmu.2019.02199

Elmore, M. R., Najafi, A. R., Koike, M. A., Dagher, N. N., Spangenberg, E. E., Rice, R. A., et al. (2014). Colony-stimulating factor 1 receptor signaling is necessary for microglia viability, unmasking a microglia progenitor cell in the adult brain. Neuron 82, 380-397. doi: 10.1016/j.neuron.2014.02.040

Epelman, S., Lavine, K. J., and Randolph, G. J. (2014). Origin and functions of tissue macrophages. Immunity 41, 21-35. doi: 10.1016/j.immuni.2014.06.013

Erblich, B., Zhu, L., Etgen, A. M., Dobrenis, K., and Pollard, J. W. (2011). Absence of colony stimulation factor-1 receptor results in loss of microglia, disrupted brain development and olfactory deficits. PLoS One 6:e26317. doi: 10.1371/journal.pone.0026317

Fehrenbach, M. K., Tjwa, M., Bechmann, I., and Krueger, M. (2018). Decreased microglial numbers in Vav1-Cre(+):dicer knock-out mice suggest a second source of microglia beyond yolk sac macrophages. Ann. Anat. 218, 190-198. doi: 10.1016/j.aanat.2018.03.004

Ferrero, G., Miserocchi, M., Di Ruggiero, E., and Wittamer, V. (2021). A csflrb mutation uncouples two waves of microglia development in zebrafish. Development 148:dev194241. doi: 10.1242/dev.194241

Ferrero, G., Mahony, C. B., Dupuis, E., Yvernogeau, L., Di Ruggiero, E., Miserocchi, M., et al. (2018). Embryonic microglia derive from primitive macrophages and are replaced by cmyb-dependent definitive microglia in zebrafish. Cell Rep. 24, 130-141. doi: 10.1016/j.celrep.2018.05.066

Fuger, P., Hefendehl, J. K., Veeraraghavalu, K., Wendeln, A. C., Schlosser, C., Obermuller, U., et al. (2017). Microglia turnover with aging and in an Alzheimer's model via long-term in vivo single-cell imaging. Nat. Neurosci. 20, 1371-1376. doi: 10.1038/nn.4631

Garceau, V., Balic, A., Garcia-Morales, C., Sauter, K. A., McGrew, M. J., Smith, J., et al. (2015). The development and maintenance of the mononuclear phagocyte system of the chick is controlled by signals from the macrophage colony-stimulating factor receptor. BMC Biol. 13:12. doi: 10.1186/s12915-0150121-9

Geirsdottir, L., David, E., Keren-Shaul, H., Weiner, A., Bohlen, S. C., Neuber, J., et al. (2019). Cross-species single-cell analysis reveals divergence of the primate microglia program. Cell 179, 1609-1622.e16. doi: 10.1016/j.cell.2019. 11.010

Gerrits, E., Heng, Y., Boddeke, E., and Eggen, B. J. L. (2020). Transcriptional profiling of microglia; current state of the art and future perspectives. Glia 68, 740-755. doi: 10.1002/glia.23767

Giannoni, P., Claeysen, S., Noe, F., and Marchi, N. (2020). Peripheral routes to neurodegeneration: passing through the blood-brain barrier. Front. Aging Neurosci. 12:3. doi: 10.3389/fnagi.2020.00003

Ginhoux, F., and Guilliams, M. (2016). Tissue-resident macrophage ontogeny and homeostasis. Immunity 44, 439-449. doi: 10.1016/j.immuni.2016.02.024

Ginhoux, F., Greter, M., Leboeuf, M., Nandi, S., See, P., Gokhan, S., et al. (2010). Fate mapping analysis reveals that adult microglia derive from primitive macrophages. Science 330, 841-845. doi: 10.1126/science.1194637

Ginhoux, F., and Jung, S. (2014). Monocytes and macrophages: developmental pathways and tissue homeostasis. Nat. Rev. Immunol. 14, 392-404. doi: $10.1038 /$ nri3671

Ginhoux, F., Lim, S., Hoeffel, G., Low, D., and Huber, T. (2013). Origin and differentiation of microglia. Front. Cell Neurosci. 7:45. doi: 10.3389/fncel.2013. 00045
Ginhoux, F., and Prinz, M. (2015). Origin of microglia: current concepts and past controversies. Cold Spring Harb Perspect. Biol. 7:a020537. doi: 10.1101/cshperspect.a020537

Goldmann, T., Wieghofer, P., Jordao, M. J., Prutek, F., Hagemeyer, N., Frenzel, K., et al. (2016). Origin, fate and dynamics of macrophages at central nervous system interfaces. Nat. Immunol. 17, 797-805. doi: 10.1038/ni.3423

Gomez Perdiguero, E., Klapproth, K., Schulz, C., Busch, K., Azzoni, E., Crozet, L., et al. (2015). Tissue-resident macrophages originate from yolk-sac-derived erythro-myeloid progenitors. Nature 518, 547-551. doi: 10.1038/nature13989

Goodbrand, I. A., and Gaze, R. M. (1991). Microglia in tadpoles of Xenopus laevis: normal distribution and the response to optic nerve injury. Anat. Embryol. (Berl) 184, 71-82. doi: 10.1007/BF01744263

Gore, A.V., Pillay, L.M., Venero Galanternik, M., and Weinstein, B.M. (2018). The zebrafish: A fintastic model for hematopoietic development and disease. Wiley Interdiscip. Rev. Dev. Biol. 7:e312. doi: 10.1002/wdev.312

Grassivaro, F., Menon, R., Acquaviva, M., Ottoboni, L., Ruffini, F., Bergamaschi, A., et al. (2020). Convergence between microglia and peripheral macrophages phenotype during development and neuroinflammation. J. Neurosci. 40, 784-795. doi: 10.1523/JNEUROSCI.1523-19.2019

Green, K. N., Crapser, J. D., and Hohsfield, L. A. (2020). To kill a microglia: a case for CSF1R inhibitors. Trends Immunol. 41, 771-784. doi: 10.1016/j.it.2020. 07.001

Greter, M., Lelios, I., Pelczar, P., Hoeffel, G., Price, J., Leboeuf, M., et al. (2012). Stroma-derived interleukin-34 controls the development and maintenance of langerhans cells and the maintenance of microglia. Immunity 37, 1050-1060. doi: 10.1016/j.immuni.2012.11.001

Guilliams, M., and Scott, C. L. (2017). Does niche competition determine the origin of tissue-resident macrophages. Nat. Rev. Immunol. 17, 451-460. doi: $10.1038 /$ nri.2017.42

Guilliams, M., Thierry, G. R., Bonnardel, J., and Bajenoff, M. (2020). Establishment and maintenance of the macrophage niche. Immunity 52, 434-451. doi: 10.1016/j.immuni.2020.02.015

Guo, Y., Hong, W., Wang, X., Zhang, P., Korner, H., Tu, J., et al. (2019). MicroRNAs in microglia: how do microRNAs affect activation, inflammation, polarization of microglia and mediate the interaction between microglia and glioma. Front. Mol. Neurosci. 12:125. doi: 10.3389/fnmol.2019.00125

Hammond, T. R., Dufort, C., Dissing-Olesen, L., Giera, S., Young, A., Wysoker, A., et al. (2019). Single-cell RNA sequencing of microglia throughout the mouse lifespan and in the injured brain reveals complex cell-state changes. Immunity 50, 253-271.e6. doi: 10.1016/j.immuni.2018.11.004

Hammond, B. P., Manek, R., Kerr, B. J., Macauley, M. S., and Plemel, J. R. (2021). Regulation of microglia population dynamics throughout development, health and disease. Glia 69, 2771-2797. doi: 10.1002/glia.24047

Hanisch, U. K. (2013). Functional diversity of microglia - how heterogeneous are they to begin with. Front. Cell Neurosci. 7:65. doi: 10.3389/fncel.2013. 00065

Hashimoto, D., Chow, A., Noizat, C., Teo, P., Beasley, M. B., Leboeuf, M., et al. (2013). Tissue-resident macrophages self-maintain locally throughout adult life with minimal contribution from circulating monocytes. Immunity 38, 792-804. doi: 10.1016/j.immuni.2013.04.004

Herbomel, P., Thisse, B., and Thisse, C. (1999). Ontogeny and behaviour of early macrophages in the zebrafish embryo. Development 126, 3735-3745.

Herbomel, P., Thisse, B., and Thisse, C. (2001). Zebrafish early macrophages colonize cephalic mesenchyme and developing brain, retina and epidermis through a M-CSF receptor-dependent invasive process. Dev. Biol. 238, 274-288. doi: 10.1006/dbio.2001.0393

Herz, J., Filiano, A. J., Smith, A., Yogev, N., and Kipnis, J. (2017). Myeloid cells in the central nervous system. Immunity 46, 943-956. doi: 10.1016/j.immuni. 2017.06.007

Hoeffel, G., Chen, J., Lavin, Y., Low, D., Almeida, F. F., See, P., et al. (2015). C$\mathrm{Myb}(+)$ erythro-myeloid progenitor-derived fetal monocytes give rise to adult tissue-resident macrophages. Immunity 42, 665-678. doi: 10.1016/j.immuni. 2015.03.011

Hoeffel, G., and Ginhoux, F. (2015). Ontogeny of tissue-resident macrophages. Front. Immunol. 6:486. doi: 10.3389/fimmu.2015.00486

Hoeffel, G., and Ginhoux, F. (2018). Fetal monocytes and the origins of tissueresident macrophages. Cell Immunol. 330, 5-15. doi: 10.1016/j.cellimm.2018. 01.001 
Huang, Y., Xu, Z., Xiong, S., Qin, G., Sun, F., Yang, J., et al. (2018a). Dual extraretinal origins of microglia in the model of retinal microglia repopulation. Cell Discov. 4:9. doi: 10.1038/s41421-018-0011-8

Huang, Y., Xu, Z., Xiong, S., Sun, F., Qin, G., Hu, G., et al. (2018b). Repopulated microglia are solely derived from the proliferation of residual microglia after acute depletion. Nat. Neurosci. 21, 530-540. doi: 10.1038/s41593-018-0090-8

Ito, D., Imai, Y., Ohsawa, K., Nakajima, K., Fukuuchi, Y., and Kohsaka, S. (1998). Microglia-specific localisation of a novel calcium binding protein, Iba1. Brain Res. Mol. Brain Res. 57, 1-9. doi: 10.1016/s0169-328x(98)00040-0

Jordao, M. J. C., Sankowski, R., Brendecke, S. M., Sagar, , Locatelli, G., Tai, Y. H., et al. (2019). Single-cell profiling identifies myeloid cell subsets with distinct fates during neuroinflammation. Science 363:eaat7554. doi: 10.1126/science. aat7554

Kana, V., Desland, F. A., Casanova-Acebes, M., Ayata, P., Badimon, A., Nabel, E., et al. (2019). CSF-1 controls cerebellar microglia and is required for motor function and social interaction. J. Exp. Med. 216, 2265-2281. doi: 10.1084/jem. 20182037

Kaur, C., Hao, A. J., Wu, C. H., and Ling, E. A. (2001). Origin of microglia. Microsc. Res. Tech. 54, 2-9. doi: 10.1002/jemt.1114

Kaur, C., Rathnasamy, G., and Ling, E. A. (2017). Biology of microglia in the Developing Brain. J. Neuropathol. Exp. Neurol. 76, 736-753. doi: 10.1093/jnen/nlx056

Kempthorne, L., Yoon, H., Madore, C., Smith, S., Wszolek, Z. K., and Rademakers, R. (2020). Loss of homeostatic microglial phenotype in CSF1R-related Leukoencephalopathy. Acta Neuropathol. Commun. 8:72. doi: 10.1186/s40478-020-00947-0

Kennedy, D. W., and Abkowitz, J. L. (1998). Mature monocytic cells enter tissues and engraft. Proc. Natl. Acad. Sci. U S A 95, 14944-14949. doi: 10.1073/pnas.95. 25.14944

Keren-Shaul, H., Spinrad, A., Weiner, A., Matcovitch-Natan, O., DvirSzternfeld, R., Ulland, T. K., et al. (2017). A unique microglia type associated with restricting development of alzheimer's disease. Cell 169, 1276-1290.e17. doi: 10.1016/j.cell.2017.05.018

Keshvari, S., Caruso, M., Teakle, N., Batoon, L., Sehgal, A., Patkar, O. L., et al. (2021). CSF1R-dependent macrophages control postnatal somatic growth and organ maturation. PLoS Genet. 17:e1009605. doi: 10.1371/journal.pgen. 1009605

Kierdorf, K., Erny, D., Goldmann, T., Sander, V., Schulz, C., Perdiguero, E. G., et al. (2013a). Microglia emerge from erythromyeloid precursors via Pu.1- and Irf8-dependent pathways. Nat. Neurosci. 16, 273-280. doi: 10.1038/nn.3318

Kierdorf, K., Katzmarski, N., Haas, C. A., and Prinz, M. (2013b). Bone marrow cell recruitment to the brain in the absence of irradiation or parabiosis bias. PLoS One 8:e58544. doi: 10.1016/j.theriogenology.2020.04.010

Kierdorf, K., and Prinz, M. (2017). Microglia in steady state. J. Clin. Invest. 127, 3201-3209. doi: 10.1172/JCI90602

Kondo, Y., Lemere, C. A., and Seabrook, T. J. (2007). Osteopetrotic (op/op) mice have reduced microglia, no Abeta deposition and no changes in dopaminergic neurons. J. Neuroinflammation 4:31. doi: 10.1186/1742-2094-4-31

Larochelle, A., Bellavance, M. A., Michaud, J. P., and Rivest, S. (2016). Bone marrow-derived macrophages and the CNS: An update on the use of experimental chimeric mouse models and bone marrow transplantation in neurological disorders. Biochim. Biophys. Acta 1862, 310-322. doi: 10.1016/j. bbadis.2015.09.017

Lauber, K., Bohn, E., Krober, S. M., Xiao, Y. J., Blumenthal, S. G., Lindemann, R. K., et al. (2003). Apoptotic cells induce migration of phagocytes via caspase-3-mediated release of a lipid attraction signal. Cell 113, 717-730. doi: 10.1016/s0092-8674(03)00422-7

Lei, F., Cui, N., Zhou, C., Chodosh, J., Vavvas, D. G., and Paschalis, E. I. (2020). CSF1R inhibition by a small-molecule inhibitor is not microglia specific; affecting hematopoiesis and the function of macrophages. Proc. Natl. Acad. Sci. U S A 117, 23336-23338. doi: 10.1073/pnas.1922788117

Leong, S. K., and Ling, E. A. (1992). Amoeboid and ramified microglia: their interrelationship and response to brain injury. Glia 6, 39-47. doi: 10.1002/glia. 440060106

Li, Q., and Barres, B. A. (2018). Microglia and macrophages in brain homeostasis and disease. Nat. Rev. Immunol. 18, 225-242. doi: 10.1038/nri.2017.125

Li, C., Chen, Y. H., and Zhang, K. (2020). Neuroprotective properties and therapeutic potential of bone marrow-derived microglia in Alzheimer's disease. Am. J. Alzheimers Dis. Other Demen. 35:1533317520927169. doi: $10.1177 / 1533317520927169$

Li, Q., Cheng, Z., Zhou, L., Darmanis, S., Neff, N. F., Okamoto, J., et al. (2019). Developmental heterogeneity of microglia and brain myeloid cells revealed by deep single-cell RNA sequencing. Neuron 101, 207-223.e10. doi: 10.1016/j. neuron.2018.12.006

Ling, E. A. (1979). Transformation of monocytes into amoeboid microglia in the corpus callosum of postnatal rats, as shown by labelling monocytes by carbon particles. J. Anat. 128, 847-858.

Ling, E. A., Penney, D., and Leblond, C. P. (1980). Use of carbon labeling to demonstrate the role of blood monocytes as precursors of the 'ameboid cells' present in the corpus callosum of postnatal rats. J. Comp. Neurol. 193, 631-657. doi: 10.1002/cne.901930304

Liu, K., Waskow, C., Liu, X., Yao, K., Hoh, J., and Nussenzweig, M. (2007). Origin of dendritic cells in peripheral lymphoid organs of mice. Nat. Immunol. 8, 578-583. doi: 10.1038/ni1462

Lopez-Atalaya, J. P., Askew, K. E., Sierra, A., and Gomez-Nicola, D. (2018). Development and maintenance of the brain's immune toolkit: microglia and non-parenchymal brain macrophages. Dev. Neurobiol. 78, 561-579. doi: 10.1002/dneu.22545

Lou, N., Takano, T., Pei, Y., Xavier, A. L., Goldman, S. A., and Nedergaard, M. (2016). Purinergic receptor P2RY12-dependent microglial closure of the injured blood-brain barrier. Proc. Natl. Acad. Sci. U S A 113, 1074-1079. doi: 10.1073/pnas.1520398113

Lund, H., Pieber, M., Parsa, R., Han, J., Grommisch, D., Ewing, E., et al. (2018). Competitive repopulation of an empty microglial niche yields functionally distinct subsets of microglia-like cells. Nat. Commun. 9:4845. doi: 10.1038/s41467-018-07295-7

Marin-Teva, J. L., Cuadros, M. A., Calvente, R., Almendros, A., and Navascues, J. (1999). Naturally occurring cell death and migration of microglial precursors in the quail retina during normal development. J. Comp. Neurol. 412, 255-275. doi: 10.1002/(SICI)1096-9861(19990920)412:2<255::AID-CNE6>3.0.CO;2-H

Marquez-Ropero, M., Benito, E., Plaza-Zabala, A., and Sierra, A. (2020). Microglial corpse clearance: lessons from macrophages. Front. Immunol. 11:506. doi: 10.3389/fimmu.2020.00506

Martin-Estebane, M., Navascues, J., Sierra-Martin, A., Martin-Guerrero, S. M., Cuadros, M. A., Carrasco, M. C., et al. (2017). Onset of microglial entry into developing quail retina coincides with increased expression of active caspase-3 and is mediated by extracellular ATP and UDP. PLoS One 12:e0182450. doi: 10.1371/journal.pone.0182450

Massengale, M., Wagers, A. J., Vogel, H., and Weissman, I. L. (2005). Hematopoietic cells maintain hematopoietic fates upon entering the brain. J. Exp. Med. 201, 1579-1589. doi: 10.1084/jem.20050030

Masuda, T., Sankowski, R., Staszewski, O., and Prinz, M. (2020). Microglia heterogeneity in the single-cell era. Cell Rep. 30, 1271-1281. doi: 10.1016/j. celrep.2020.01.010

Matcovitch-Natan, O., Winter, D. R., Giladi, A., Vargas Aguilar, S., Spinrad, A., Sarrazin, S., et al. (2016). Microglia development follows a stepwise program to regulate brain homeostasis. Science 335:aad8670. doi: 10.1126/science.aad8670

McGrath, K. E., Frame, J. M., Fegan, K. H., Bowen, J. R., Conway, S. J., Catherman, S. C., et al. (2015). Distinct sources of hematopoietic progenitors emerge before HSCs and provide functional blood cells in the mammalian embryo. Cell Rep. 11, 1892-1904. doi: 10.1016/j.celrep.2015.05.036

McKercher, S. R., Torbett, B. E., Anderson, K. L., Henkel, G. W., Vestal, D. J., Baribault, H., et al. (1996). Targeted disruption of the PU.1 gene results in multiple hematopoietic abnormalities. EMBO J. 15, 5647-5658. doi: 10.1002/j. 1460-2075.1996.tb00949.x

McKinsey, G. L., Lizama, C. O., Keown-Lang, A. E., Niu, A., Santander, N., Larpthaveesarp, A., et al. (2020). A new genetic strategy for targeting microglia in development and disease. eLife 9:e54590. doi: 10.7554/eLife. 54590

McPherson, S. W., Heuss, N. D., Lehmann, U., Roehrich, H., Abedin, M., and Gregerson, D. S. (2019). The retinal environment induces microglia-like properties in recruited myeloid cells. J. Neuroinflammation 16:151. doi: 10.1186/s12974-019-1546-9

Menassa, D. A., and Gomez-Nicola, D. (2018). Microglial dynamics during human brain development. Front. Immunol. 9:1014. doi: 10.3389/fimmu.2018. 01014 
Menegatti, S., de Kruijf, M., Garcia-Alegria, E., Lacaud, G., and Kouskoff, V. (2019). Transcriptional control of blood cell emergence. FEBS Lett. 593, 3304-3315. doi: 10.1002/1873-3468.13585

Mesquida-Veny, F., Del Rio, J. A., and Hervera, A. (2021). Macrophagic and microglial complexity after neuronal injury. Prog. Neurobiol. 200:101970. doi: 10.1016/j.pneurobio.2020.101970

Mildner, A., Schmidt, H., Nitsche, M., Merkler, D., Hanisch, U. K., Mack, M., et al. (2007). Microglia in the adult brain arise from Ly-6ChiCCR2+ monocytes only under defined host conditions. Nat. Neurosci. 10, 1544-1553. doi: $10.1038 / \mathrm{nn} 2015$

Minten, C., Terry, R., Deffrasnes, C., King, N. J., and Campbell, I. L. (2012). IFN regulatory factor 8 is a key constitutive determinant of the morphological and molecular properties of microglia in the CNS. PLoS One 7:e49851. doi: 10.1371/journal.pone.0049851

Mondo, E., Becker, S. C., Kautzman, A. G., Schifferer, M., Baer, C. E., Chen, J., et al. (2020). A Developmental analysis of juxtavascular microglia dynamics and interactions with the vasculature. J. Neurosci. 40, 6503-6521. doi: 10.1523/JNEUROSCI.3006-19.2020

Morales-Ropero, J. M., Arroyo-Urea, S., Neubrand, V. E., Martin-Oliva, D., Marin-Teva, J. L., Cuadros, M. A., et al. (2021). The endoplasmic reticulum $\mathrm{Ca}(2+)$-ATPase SERCA2b is upregulated in activated microglia and its inhibition causes opposite effects on migration and phagocytosis. Glia 69, 842-857. doi: 10.1002/glia.23931

Murabe, Y., and Sano, Y. (1981). Thiaminepyrophosphatase activity in the plasma membrane of microglia. Histochemistry 71, 45-52. doi: 10.1007/BF00 592569

Murabe, Y., and Sano, Y. (1982). Morphological studies on neuroglia. V. Microglial cells in the cerebral cortex of the rat, with special reference to their possible involvement in synaptic function. Cell Tissue Res. 223, 493-506. doi: $10.1007 / \mathrm{BF} 00218471$

Natoli, R., Fernando, N., Madigan, M., Chu-Tan, J. A., Valter, K., Provis, J., et al. (2017). Microglia-derived IL-1beta promotes chemokine expression by Muller cells and RPE in focal retinal degeneration. Mol. Neurodegener. 12:31. doi: 10.1186/s13024-017-0175-y

Navascues, J., Moujahid, A., Almendros, A., Marin-Teva, J. L., and Cuadros, M. A. (1995). Origin of microglia in the quail retina: central-to-peripheral and vitrealto-scleral migration of microglial precursors during development. J. Comp. Neurol. 354, 209-228. doi: 10.1002/cne.903540205

Ng, P. Y., McNeely, T. L., and Baker, D. J. (2021). Untangling senescent and damage-associated microglia in the aging and diseased brain. FEBS J. doi: 10.1111/febs.16315. [Online ahead of print].

O’Koren, E. G., Yu, C., Klingeborn, M., Wong, A. Y. W., Prigge, C. L., Mathew, R., et al. (2019). Microglial function is distinct in different anatomical locations during retinal homeostasis and degeneration. Immunity 50, 723-737.e7. doi: 10.1016/j.immuni.2019.02.007

Pan, W., Stone, K. P., Hsuchou, H., Manda, V. K., Zhang, Y., and Kastin, A. J. (2011). Cytokine signaling modulates blood-brain barrier function. Curr. Pharm. Des. 17, 3729-3740. doi: 10.2174/138161211798220918

Parkhurst, C. N., Yang, G., Ninan, I., Savas, J. N., Yates 3rd, J. R., Lafaille, J. J., et al. (2013). Microglia promote learning-dependent synapse formation through brain-derived neurotrophic factor. Cell 155, 1596-1609. doi: 10.1016/j.cell. 2013.11.030

Paschalis, E. I., Lei, F., Zhou, C., Kapoulea, V., Dana, R., Chodosh, J., et al. (2018). Permanent neuroglial remodeling of the retina following infiltration of CSF1R inhibition-resistant peripheral monocytes. Proc. Natl. Acad. Sci. U S A 115, E11359-E11368. doi: 10.1073/pnas.1807123115

Patkar, O. L., Caruso, M., Teakle, N., Keshvari, S., Bush, S. J., Pridans, C., et al. (2021). Analysis of homozygous and heterozygous Csf1r knockout in the rat as a model for understanding microglial function in brain development and the impacts of human CSF1R mutations. Neurobiol. Dis. 151:105268. doi: 10.1016/j. nbd.2021.105268

Perry, V. H., Hume, D. A., and Gordon, S. (1985). Immunohistochemical localization of macrophages and microglia in the adult and developing mouse brain. Neuroscience 15, 313-326. doi: 10.1016/0306-4522(85)90215-5

Plemel, J. R., Stratton, J. A., Michaels, N. J., Rawji, K. S., Zhang, E., Sinha, S., et al. (2020). Microglia response following acute demyelination is heterogeneous and limits infiltrating macrophage dispersion. Sci. Adv. 6:eaay6324. doi: 10.1126/sciadv.aay6324
Pont-Lezica, L., Beumer, W., Colasse, S., Drexhage, H., Versnel, M., and Bessis, A. (2014). Microglia shape corpus callosum axon tract fasciculation: functional impact of prenatal inflammation. Eur. J. Neurosci. 39, 1551-1557. doi: 10.1111/ejn.12508

Priller, J., Flugel, A., Wehner, T., Boentert, M., Haas, C. A., Prinz, M., et al. (2001). Targeting gene-modified hematopoietic cells to the central nervous system: use of green fluorescent protein uncovers microglial engraftment. Nat. Med. 7, 1356-1361. doi: 10.1038/nm1201-1356

Prinz, M., Erny, D., and Hagemeyer, N. (2017). Ontogeny and homeostasis of CNS myeloid cells. Nat. Immunol. 18, 385-392. doi: 10.1038/ ni. 3703

Prinz, M., Jung, S., and Priller, J. (2019). Microglia biology: one century of evolving concepts. Cell 179, 292-311. doi: 10.1016/j.cell.2019.08.053

Rakic, S., and Zecevic, N. (2000). Programmed cell death in the developing human telencephalon. Eur. J. Neurosci. 12, 2721-2734. doi: 10.1046/j.1460-9568.2000. 00153.x

Ratajczak, M. Z., Adamiak, M., Plonka, M., Abdel-Latif, A., and Ratajczak, J. (2018). Mobilization of hematopoietic stem cells as a result of innate immunity-mediated sterile inflammation in the bone marrow microenvironment-the involvement of extracellular nucleotides and purinergic signaling. Leukemia 32, 1116-1123. doi: 10.1038/s41375-018 $-0087-z$

Reaux-Le Goazigo, A., Van Steenwinckel, J., Rostene, W., and Melik Parsadaniantz, S. (2013). Current status of chemokines in the adult CNS. Prog. Neurobiol. 104, 67-92. doi: 10.1016/j.pneurobio.2013. 02.001

Rojo, R., Raper, A., Ozdemir, D. D., Lefevre, L., Grabert, K., WollscheidLengeling, E., et al. (2019). Deletion of a Csf1r enhancer selectively impacts CSF1R expression and development of tissue macrophage populations. Nat. Commun. 10:3215. doi: 10.1038/s41467-019-11053-8

Rosin, J. M., Vora, S. R., and Kurrasch, D. M. (2018). Depletion of embryonic microglia using the CSF1R inhibitor PLX5622 has adverse sex-specific effects on mice, including accelerated weight gain, hyperactivity and anxiolytic-like behaviour. Brain Behav. Immun. 73, 682-697. doi: 10.1016/j.bbi.2018. 07.023

Rossi, F., Casano, A. M., Henke, K., Richter, K., and Peri, F. (2015). The SLC7A7 transporter identifies microglial precursors prior to entry into the brain. Cell Rep. 11, 1008-1017. doi: 10.1016/j.celrep.2015. 04.028

Samokhvalov, I. M., Samokhvalova, N. I., and Nishikawa, S. (2007). Cell tracing shows the contribution of the yolk sac to adult haematopoiesis. Nature 446, 1056-1061. doi: 10.1038/nature05725

Sanchez-Lopez, A., Cuadros, M. A., Calvente, R., Tassi, M., Marin-Teva, J. L., and Navascues, J. (2004). Radial migration of developing microglial cells in quail retina: a confocal microscopy study. Glia 46, 261-273. doi: 10.1002/glia. 20007

Santos, A. M., Calvente, R., Tassi, M., Carrasco, M. C., Martin-Oliva, D., MarinTeva, J. L., et al. (2008). Embryonic and postnatal development of microglial cells in the mouse retina. J. Comp. Neurol. 506, 224-239. doi: 10.1002/cne.21538

Santos, A. M., Martin-Oliva, D., Ferrer-Martin, R. M., Tassi, M., Calvente, R., Sierra, A., et al. (2010). Microglial response to light-induced photoreceptor degeneration in the mouse retina. J. Comp. Neurol. 518, 477-492. doi: $10.1002 /$ cne.22227

Savage, J. C., Carrier, M., and Tremblay, M.-É. (2019). “Morphology of microglia across contexts of health and disease," in Methods in Molecular Biology, eds O. Garaschuk, and A. Verkhratsky (New York: Humana Press), 13-26. doi: 10.1007/978-1-4939-9658-2_2

Schilling, T., Nitsch, R., Heinemann, U., Haas, D., and Eder, C. (2001). Astrocytereleased cytokines induce ramification and outward $\mathrm{K}+$ channel expression in microglia via distinct signalling pathways. Eur. J. Neurosci. 14, 463-473. doi: 10.1046/j.0953-816x.2001.01661.x

Schreier, S., and Triampo, W. (2020). The blood circulating rare cell population. what is it and what is it good for? Cells 9:790. doi: 10.3390/cells90 40790

Schulz, C., Gomez Perdiguero, E., Chorro, L., Szabo-Rogers, H., Cagnard, N., Kierdorf, K., et al. (2012). A lineage of myeloid cells independent of Myb and hematopoietic stem cells. Science 336, 86-90. doi: 10.1126/science.12 19179 
Sevenich, L. (2018). Brain-resident microglia and blood-borne macrophages orchestrate central nervous system inflammation in neurodegenerative disorders and brain cancer. Front. Immunol. 9:697. doi: 10.3389/fimmu.2018. 00697

Shemer, A., Grozovski, J., Tay, T. L., Tao, J., Volaski, A., Suss, P., et al. (2018). Engrafted parenchymal brain macrophages differ from microglia in transcriptome, chromatin landscape and response to challenge. Nat. Commun. 9:5206. doi: 10.1038/s41467-018-07548-5

Sheng, J., Ruedl, C., and Karjalainen, K. (2015). Most tissue-resident macrophages except microglia are derived from fetal hematopoietic stem cells. Immunity 43 , 382-393. doi: 10.1016/j.immuni.2015.07.016

Sieger, D., Moritz, C., Ziegenhals, T., Prykhozhij, S., and Peri, F. (2012). Longrange $\mathrm{Ca} 2+$ waves transmit brain-damage signals to microglia. Dev. Cell 22, 1138-1148. doi: 10.1016/j.devcel.2012.04.012

Sierra, A., de Castro, F., Del Rio-Hortega, J., Rafael Iglesias-Rozas, J., Garrosa, M., and Kettenmann, H. (2016). The "Big-Bang" for modern glial biology: translation and comments on Pio del Rio-Hortega 1919 series of papers on microglia. Glia 64, 1801-1840. doi: 10.1002/glia. 23046

Sievers, J., Parwaresch, R., and Wottge, H. U. (1994). Blood monocytes and spleen macrophages differentiate into microglia-like cells on monolayers of astrocytes: morphology. Glia 12, 245-258. doi: 10.1002/glia.440120402

Simard, A. R., and Rivest, S. (2004). Bone marrow stem cells have the ability to populate the entire central nervous system into fully differentiated parenchymal microglia. FASEB J. 18, 998-1000. doi: 10.1096/fj.04-1517fje

Smolders, S. M., Kessels, S., Vangansewinkel, T., Rigo, J. M., Legendre, P., and Brone, B. (2019). Microglia: brain cells on the move. Prog. Neurobiol. 178:101612. doi: 10.1016/j.pneurobio.2019.04.001

Sorokin, S. P., Hoyt, R. F., Jr., Blunt, D. G., and McNelly, N. A. (1992). Macrophage development: II. Early ontogeny of macrophage populations in brain, liver and lungs of rat embryos as revealed by a lectin marker. Anat. Rec. 232, 527-550. doi: 10.1002/ar.1092320410

Soulet, D., and Rivest, S. (2008). Bone-marrow-derived microglia: myth or reality? Curr. Opin. Pharmacol. 8, 508-518. doi: 10.1016/j.coph.2008.04.002

Squarzoni, P., Oller, G., Hoeffel, G., Pont-Lezica, L., Rostaing, P., Low, D., et al. (2014). Microglia modulate wiring of the embryonic forebrain. Cell Rep. 8, 1271-1279. doi: 10.1016/j.celrep.2014.07.042

Stratoulias, V., Venero, J. L., Tremblay, M. E., and Joseph, B. (2019). Microglial subtypes: diversity within the microglial community. EMBO J. 38:e101997. doi: $10.15252 /$ embj.2019101997

Stremmel, C., Schuchert, R., Wagner, F., Thaler, R., Weinberger, T., Pick, R., et al. (2018). Yolk sac macrophage progenitors traffic to the embryo during defined stages of development. Nat. Commun. 9:75. doi: 10.1038/s41467-017-02492-2

Takahashi, K., Naito, M., and Takeya, M. (1996). Development and heterogeneity of macrophages and their related cells through their differentiation pathways. Pathol. Int. 46, 473-485. doi: 10.1111/j.1440-1827.1996.tb03641.x

Takahashi, K., Yamamura, F., and Naito, M. (1989). Differentiation, maturation and proliferation of macrophages in the mouse yolk sac: a light-microscopic, enzyme-cytochemical, immunohistochemical and ultrastructural study. J. Leukoc. Biol. 45, 87-96. doi: 10.1002/jlb.45.2.87

Tan, Y. L., Yuan, Y., and Tian, L. (2020). Microglial regional heterogeneity and its role in the brain. Mol. Psychiatry 25, 351-367. doi: 10.1038/s41380-019-0609-8

Tavian, M., Biasch, K., Sinka, L., Vallet, J., and Peault, B. (2010). Embryonic origin of human hematopoiesis. Int. J. Dev. Biol. 54, 1061-1065. doi: 10.1387/ijdb. $103097 \mathrm{mt}$

Taylor, S., Mehina, E., White, E., Reeson, P., Yongblah, K., Doyle, K. P., et al. (2018). Suppressing interferon-gamma stimulates microglial responses and repair of microbleeds in the diabetic brain. J. Neurosci. 38, 8707-8722. doi: 10.1523/JNEUROSCI.0734-18.2018

Thion, M. S., and Garel, S. (2017). On place and time: microglia in embryonic and perinatal brain development. Curr. Opin. Neurobiol. 47, 121-130. doi: 10.1016/j.conb.2017.10.004

Thion, M. S., Ginhoux, F., and Garel, S. (2018a). Microglia and early brain development: an intimate journey. Science 362, 185-189. doi: 10.1126/science. aat 0474

Thion, M. S., Low, D., Silvin, A., Chen, J., Grisel, P., Schulte-Schrepping, J., et al. (2018b). Microbiome influences prenatal and adult microglia in a sex-specific manner. Cell 172, 500-516.e16. doi: 10.1016/j.cell.2017.11.042
Thurgur, H., and Pinteaux, E. (2019). Microglia in the neurovascular unit: bloodbrain barrier-microglia interactions after central nervous system disorders. Neuroscience 405, 55-67. doi: 10.1016/j.neuroscience.2018.06.046

Toyoshima, Y., Sekiguchi, S., Negishi, T., Nakamura, S., Ihara, T., Ishii, Y., et al. (2012). Differentiation of neural cells in the fetal cerebral cortex of cynomolgus monkeys (Macaca fascicularis). Comp. Med. 62, 53-60.

Utz, S. G., See, P., Mildenberger, W., Thion, M. S., Silvin, A., Lutz, M., et al. (2020). Early fate defines microglia and non-parenchymal brain macrophage development. Cell 181, 557-573.e18. doi: 10.1016/j.cell.2020.03.021

van de Laar, L., Saelens, W., De Prijck, S., Martens, L., Scott, C. L., Van Isterdael, G., et al. (2016). Yolk sac macrophages, fetal liver and adult monocytes can colonize an empty niche and develop into functional tissue-resident macrophages. Immunity 44, 755-768. doi: 10.1016/j.immuni.2016.02.017

van Furth, R., Cohn, Z. A., Hirsch, J. G., Humphrey, J. H., Spector, W. G., and Langevoort, H. L. (1972). The mononuclear phagocyte system: a new classification of macrophages, monocytes and their precursor cells. Bull. World Health Organ. 46, 845-852.

Varol, D., Mildner, A., Blank, T., Shemer, A., Barashi, N., Yona, S., et al. (2017). Dicer deficiency differentially impacts microglia of the developing and adult brain. Immunity 46, 1030-1044.e8. doi: 10.1016/j.immuni.2017.05.003

Varvel, N. H., Grathwohl, S. A., Baumann, F., Liebig, C., Bosch, A., Brawek, B., et al. (2012). Microglial repopulation model reveals a robust homeostatic process for replacing CNS myeloid cells. Proc. Natl. Acad. Sci. U S A 109, 18150-18155. doi: 10.1073/pnas.1210150109

Verney, C., Monier, A., Fallet-Bianco, C., and Gressens, P. (2010). Early microglial colonization of the human forebrain and possible involvement in periventricular white-matter injury of preterm infants. J. Anat. 217, 436-448. doi: 10.1111/j.1469-7580.2010.01245.x

Waisman, A., Ginhoux, F., Greter, M., and Bruttger, J. (2015). Homeostasis of microglia in the adult brain: review of novel microglia depletion systems. Trends Immunol. 36, 625-636. doi: 10.1016/j.it.2015.08.005

Wang, Y., Szretter, K. J., Vermi, W., Gilfillan, S., Rossini, C., Cella, M., et al. (2012). IL-34 is a tissue-restricted ligand of CSF1R required for the development of langerhans cells and microglia. Nat. Immunol. 13, 753-760. doi: 10.1038/ ni. 2360

Wettschureck, N., Strilic, B., and Offermanns, S. (2019). Passing the vascular barrier: endothelial signaling processes controlling extravasation. Physiol. Rev. 99, 1467-1525. doi: 10.1152/physrev.00037.2018

Wu, S., Xue, R., Hassan, S., Nguyen, T. M. L., Wang, T., Pan, H., et al. (2018). Il34-Csf1r pathway regulates the migration and colonization of microglial precursors. Dev. Cell 46, 552-563.e4. doi: 10.1016/j.devcel.2018.08.005

Xu, Z., Rao, Y., Huang, Y., Zhou, T., Feng, R., Xiong, S., et al. (2020). Efficient strategies for microglia replacement in the central nervous system. Cell Rep. 33:108443. doi: 10.1016/j.celrep.2020.108443

Xu, J., Wang, T., Wu, Y., Jin, W., and Wen, Z. (2016). Microglia colonization of developing zebrafish midbrain is promoted by apoptotic neuron and lysophosphatidylcholine. Dev. Cell 38, 214-222. doi: 10.1016/j.devcel.2016. 06.018

Xu, J., Zhu, L., He, S., Wu, Y., Jin, W., Yu, T., et al. (2015). Temporal-spatial resolution fate mapping reveals distinct origins for embryonic and adult microglia in zebrafish. Dev. Cell 34, 632-641. doi: 10.1016/j.devcel.2015.08.018

Yosef, N., Vadakkan, T. J., Park, J. H., Poche, R. A., Thomas, J. L., and Dickinson, M. E. (2018). The phenotypic and functional properties of mouse yolk-sac-derived embryonic macrophages. Dev. Biol. 442, 138-154. doi: 10.1016/j.ydbio.2018.07.009

Youshani, A. S., Rowlston, S., O'Leary, C., Forte, G., Parker, H., Liao, A., et al. (2019). Non-myeloablative busulfan chimeric mouse models are less pro-inflammatory than head-shielded irradiation for studying immune cell interactions in brain tumours. J. Neuroinflammation 16:25. doi: 10.1186/s12974-019-1410-y

Yu, X., Ji, C., and Shao, A. (2020). Neurovascular unit dysfunction and neurodegenerative disorders. Front. Neurosci. 14:334. doi: 10.3389/fnins.2020. 00334

Yzaguirre, A. D., de Bruijn, M. F., and Speck, N. A. (2017). The role of Runx1 in embryonic blood cell formation. Adv. Exp. Med. Biol. 962, 47-64. doi: 10.1007/978-981-10-3233-2_4

Zhan, L., Krabbe, G., Du, F., Jones, I., Reichert, M. C., Telpoukhovskaia, M., et al. (2019). Proximal recolonization by self-renewing microglia re-establishes 
microglial homeostasis in the adult mouse brain. PLoS Biol. 17:e3000134. doi: 10.1371/journal.pbio.3000134

Zhang, Y., Zhao, L., Wang, X., Ma, W., Lazere, A., Qian, H. H., et al. (2018). Repopulating retinal microglia restore endogenous organization and function under CX3CL1-CX3CR1 regulation. Sci. Adv. 4:eaap8492. doi: 10.1126/sciadv. aap8492

Zia, S., Rawji, K. S., Michaels, N. J., Burr, M., Kerr, B. J., Healy, L. M., et al. (2020). Microglia diversity in health and multiple sclerosis. Front. Immunol. 11:588021. doi: 10.3389/fimmu.2020.588021

Conflict of Interest: The authors declare that the research was conducted in the absence of any commercial or financial relationships that could be construed as a potential conflict of interest.
Publisher's Note: All claims expressed in this article are solely those of the authors and do not necessarily represent those of their affiliated organizations, or those of the publisher, the editors and the reviewers. Any product that may be evaluated in this article, or claim that may be made by its manufacturer, is not guaranteed or endorsed by the publisher.

Copyright (c) 2022 Cuadros, Sepulveda, Martin-Oliva, Marín-Teva and Neubrand. This is an open-access article distributed under the terms of the Creative Commons Attribution License (CC BY). The use, distribution or reproduction in other forums is permitted, provided the original author(s) and the copyright owner(s) are credited and that the original publication in this journal is cited, in accordance with accepted academic practice. No use, distribution or reproduction is permitted which does not comply with these terms. 